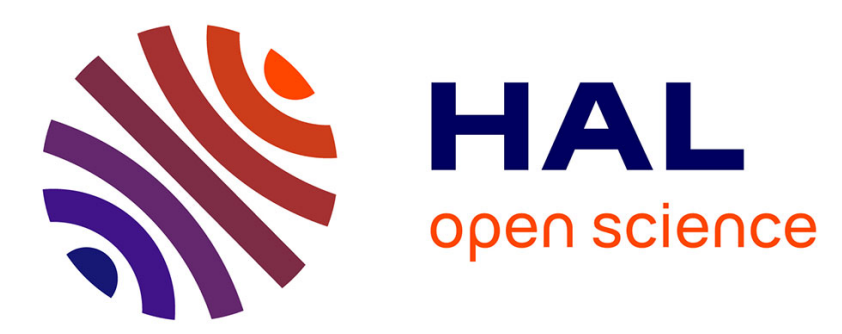

\title{
Review of patient-specific simulations of transcatheter aortic valve implantation
}

\author{
P Vy, Vincent Auffret, Pierre Badel, Michel Rochette, Hervé Le Breton, \\ Pascal Haigron, Stéphane Avril
}

\section{- To cite this version:}

P Vy, Vincent Auffret, Pierre Badel, Michel Rochette, Hervé Le Breton, et al.. Review of patientspecific simulations of transcatheter aortic valve implantation. International Journal of Advances in Engineering Sciences and Applied Mathematics, 2016, 8 (1), pp.2-24. 10.1007/s12572-015-0139-9 . hal-01196296

\section{HAL Id: hal-01196296 \\ https://hal-univ-rennes1.archives-ouvertes.fr/hal-01196296}

Submitted on 9 Sep 2015

HAL is a multi-disciplinary open access archive for the deposit and dissemination of scientific research documents, whether they are published or not. The documents may come from teaching and research institutions in France or abroad, or from public or private research centers.
L'archive ouverte pluridisciplinaire HAL, est destinée au dépôt et à la diffusion de documents scientifiques de niveau recherche, publiés ou non, émanant des établissements d'enseignement et de recherche français ou étrangers, des laboratoires publics ou privés. 


\title{
Review of Patient-Specific Simulations of Transcatheter Aortic Valve Implantation
}

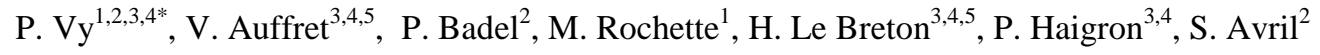 \\ ${ }^{1}$ ANSYS France, Villeurbanne, F-69100, France \\ ${ }^{2}$ Ecole Nationale Supérieure des Mines de Saint-Etienne, CIS-EMSE, CNRS:UMR5307, LGF, F-42023 Saint \\ Etienne, France \\ ${ }^{3}$ INSERM, U1099, Rennes, F-35000, France \\ ${ }^{4}$ Université de Rennes 1, LTSI, F-35000 Rennes, France \\ ${ }^{5}$ CHU Rennes, Service de Cardiologie et Maladies Vasculaires, Rennes, F-35000, France \\ * Author for correspondence. E-mail address: phuoc.vy@ ansys.com
}

\section{Keywords}

Heart valve, aortic valve, finite element analysis, patient-specific, numerical simulation, transcatheter aortic valve implantation

\begin{abstract}
Transcatheter Aortic Valve Implantation (TAVI) accounts for one of the most promising new cardiovascular procedures. This minimally invasive technique is still at its early stage and is constantly developing thanks to imaging techniques, computer science, biomechanics and technologies of prosthesis and delivery tools. As a result, patient-specific simulation can find an exciting playground in TAVI. It canexpress its potential by providing the clinicians with powerful decision support, offering great assistance in their workflow. Through a review of the current scientific field, we try to identify the challenges and future evolutions of patient-specific simulation for TAVI. This review article is an attempt to summarize and coordinate data scattered across the literature about patient-specific biomechanical simulation for TAVI.
\end{abstract}




\section{Introduction}

Aortic Stenosis (AS) is a cardiovascular disease affecting the heart's aortic valve. Surgical aortic valve replacement (AVR or SAVR) is the current standard treatment. Unfortunately, it requires thoracotomy and cardiopulmonary bypass to reach and repair the damaged zone. These difficult procedures can be especially lifethreatening for elderly patients and require a long recovery period. Fig.1 shows a picture of an on-going AVR.

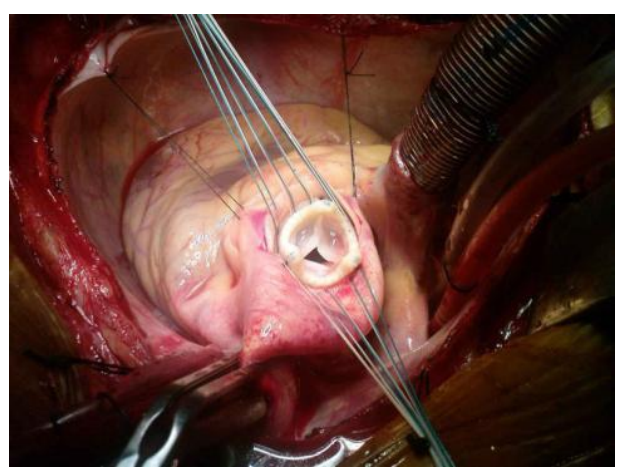

Fig.1 AVR, surgical implantation of a bioprosthetic valve, cf section 1 for more detail (reproduced with permission of Dr. Sukumar Mehta)

Transcatheter Aortic Valve Implantation (TAVI) has emerged as a promising solution for AS treatment. This novel technique consists in delivering a bioprosthesis into the heart, through the patient's arteries. This minimally invasive procedure significantly shortens recovery time and can successfully treat inoperable or very high-risk patients. Indeed, TAVI has proven to be superior to AVR in such populations [1][2][3]. However, TAVI is a recent procedure, with the earliest implantations dating back to 2002 [4], leading TAVI prostheses to continue struggling to outperform AVR prostheses in various aspects [5]. Indeed, this method of treatment has been limited to high-risk patients due to numerous concerns, such as complications that are particularly difficult to deal with [6][7] and limited follow-up data about prosthesis durability.

In order to predict the complications that may occur, a promising approach is taking into account the specific details of the anatomy and characteristics of arteries, as they can differ greatly from one individual to another. Therefore, patient-specific simulations are powerful tools in this context. There is little doubt that patientspecific simulation will help TAVI expand its recommended patient population. Still, TAVI is challenging to model and simulate accurately. Patient-specific simulation studies only started a few years ago[8]. As a result, comparative studies on large-scale data are lacking and there is no reliable and proven model. Instead, those studies are dedicated to developing increasingly accurate models. This review article will shed some light on these advances.

The first part of this review provides general information for readers who are unfamiliar with TAVI. It details the context of AS, the procedure of TAVI and the common complications that follow it. The second part will offer an overview of the evolution and new aspects in patient-specific simulation. The third part will look at the choices made in each study to model TAVI. The last part will expose how simulation results have been exploited so far.

\section{Clinical context}

This first section provides clarification about the general context of Aortic Stenosis (AS) and Transcatheter Aortic Valve Implantation (TAVI). It is mainly intended for readers unfamiliar with the cardiovascular field. As it expands the points in the introduction, readers may skip to the second section concerning patient-specific simulation.

\subsection{Aortic Stenosis}




\section{General considerations}

The heart pumps blood and guarantees the necessary blood irrigation across the human body. In other words, the heart provides mechanical energy to make the blood flow. Naturally, an obstacle in the blood vessels or failure of a component of the heart may dissipate this mechanical energy. The heart will be forced to compensate this energy loss to maintain adequate blood flow. This additional burden can exceed the heart's capacity and lead to heart failure. This is precisely the situation that happens in the case of AS.
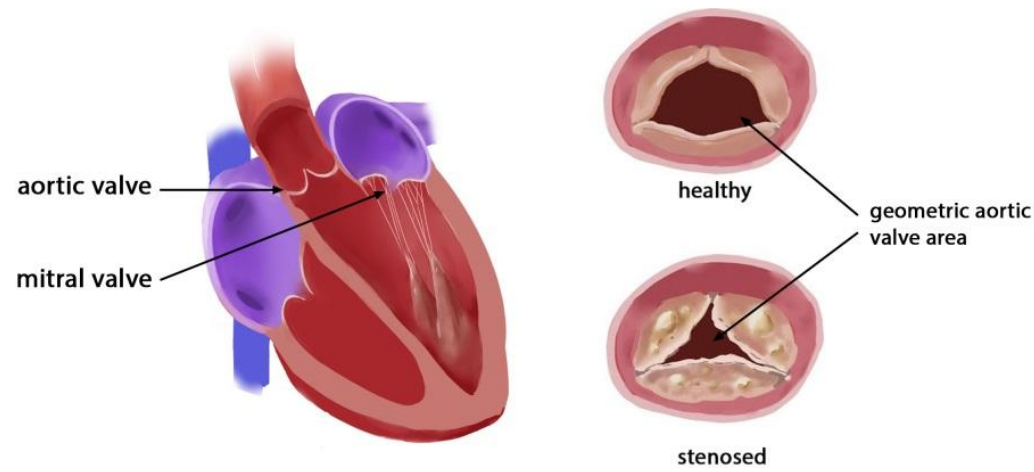

fig.2Left, aortic valve anatomy; right,upper view of fully open healthy and calcified valve during systole

The heart includes four valves which are essential to its pumping function. In particular, the Aortic Valve separates the left ventricle from the aorta. Through three mobile leaflets, which open during the left ventricle contraction (systole) and close during the left ventricle relaxation (diastole), it maintains a unidirectional blood flow from the heart to the aorta. Then the aorta and further arteries lead to all the tissues that require blood: the heart itself, the brain, organs, muscles, etc.

AS is defined by a decreased effective area of the aortic valve and is considered severe when this area is below $1 \mathrm{~cm}^{2}$ or $0.6 \mathrm{~cm}^{2} / \mathrm{m}^{2}$ [9]. It is the most common valvular disease with increasing incidence in aging population affecting almost $10 \%$ of octogenarians[10][11]. In a large majority of cases, this is because of heavy calcifications of its leaflets. Fig. 2 shows how the calcified valve behaves in comparison to a normal valve during systole. In a way, AS is the apparition of an obstacle right at the start of the arterial system. From a fluid dynamic point of view, the flow cross-section (aortic valve area) of the blood is significantly reduced at the passage of the calcified aortic valve. The reduction of this area may cause a turbulent mixing phenomenon, which is depicted in Fig.3. It shows a side view of the aortic valve. The central jet velocity increases at the choke point as its pressure drops. Then, the central jet progressively loses velocity and recovers pressure. A portion of the central jet is redirected to the turbulent mixing zone, where part of the initial energy provided by the heart is dissipated into heat [12][13][14]. The turbulent mixing zone is at the interface of the central jet and the recirculation zone, where vorticities helps closing the valve at the end of systole. Lacking energy, the central jet may not recover enough pressure. From a clinical point of view, the patient would eventually suffer low cardiac output and low arterial pressure, as the remaining mechanical energy is insufficient to pump the blood to meet the body's needs. In practice, however, a compensation mechanism allows the heart to maintain adequate cardiac output through left ventricular hypertrophy before reaching heart failure. 

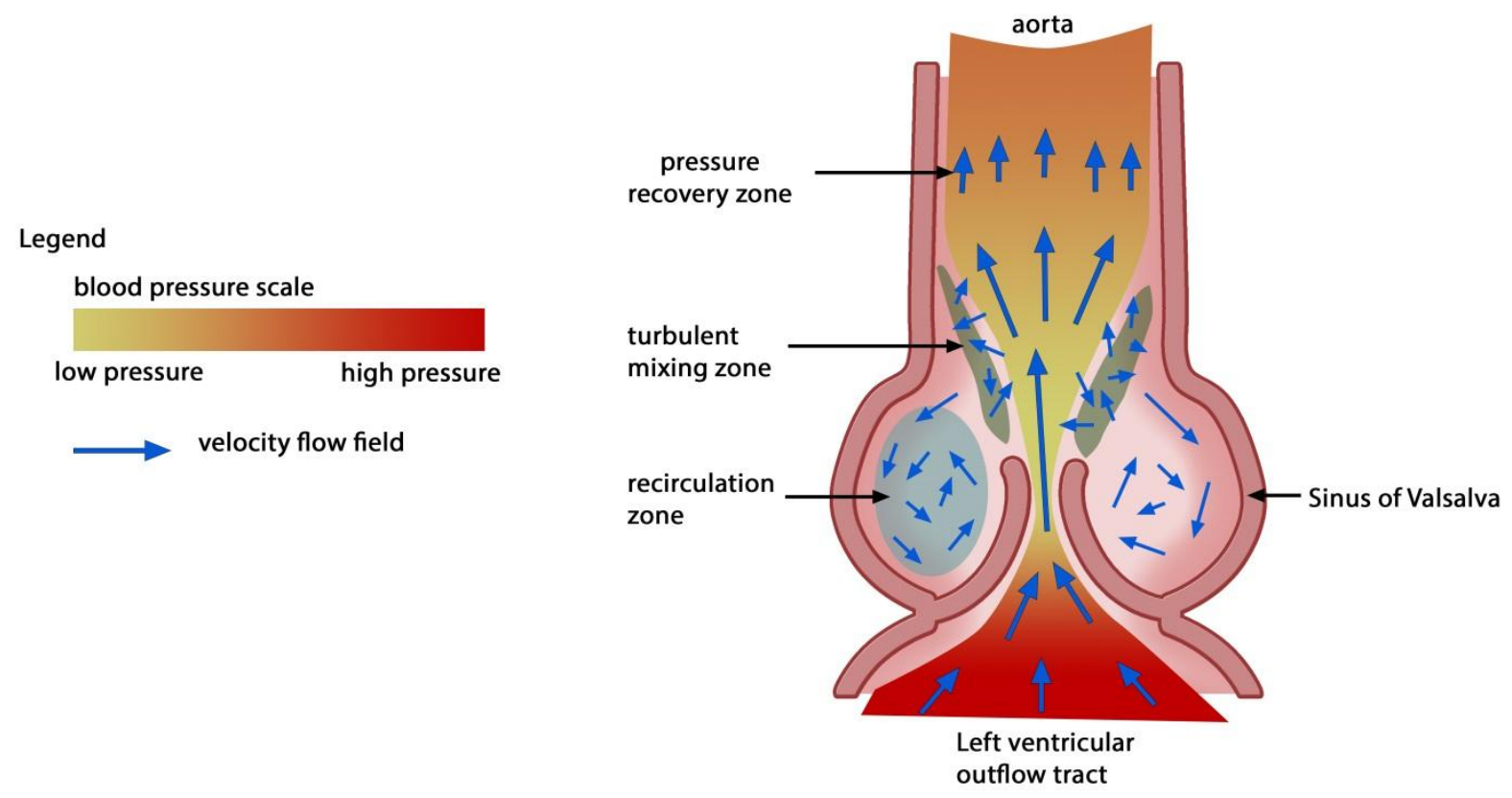

Fig.3Side cut view of aortic valve. Dissipation of mechanical energy is mainly located in the turbulent mixing zone

\section{Symptoms}

AS has a slow onset as the heart can only tolerate reduction of the aortic valve area to some extent. Symptoms usually appear when AS is at a severe stage and quickly progresses thereafter [15]. Severe AS requires urgent treatment [16]. As previously stated, the heart eventually fails to provide the necessary mechanical energy to maintain an adequate cardiac output and end-diastolic left ventricular pressure rises. This situation is called congestive heart failure and can lead to a fatal outcome. The most common symptoms of severe AS are shortness of breath (dyspnea), chest pain and syncope typically during exercise but acute congestive heart failure (pulmonary edema) and even sudden cardiac death may also occur.

\section{Causes}

The main mechanism is the growth of calcifications on the leaflets known as degenerative AS which usually concerns the elderly. The calcifications stiffen the leaflets as they grow on it and hinder the opening and/or the closing of the valve. Another cause is the congenital defect known as bicuspid valve. The aortic valve possesses two leaflets instead of three, resulting in faster degeneration of the aortic valve. Indeed, bicuspid aortic valve alone is not sufficient to cause severe aortic stenosis by itself, but rather, accelerates the degeneration and calcification of the aortic valveleading to an earlier onset of aortic stenosis [17].

\section{Standard treatment}

Surgical Aortic Valve Replacement (AVR or SAVR) is established as the gold standard for the treatment of AS. The surgeon accesses the heart through thoracotomy and cardiopulmonary bypass. The native calcified leaflets are removed and a prosthesis is sewn into the aortic root, cf Fig.1. TAVI prosthesis are limited to bio-prosthesis (leaflets sewn into a stent c.f. Fig.5), because the percutaneous access through arteries requires crimping the prosthesis to fit in the vessels (c.f. section 1.2). On the other hand, AVR prosthesis can have different designs that do not require to be crimped, thanks to the direct access to the heart through thoracotomy. Therefore, it is possible to implant mechanical valve with high structural durability that can outlast bio-prosthesis. However, mechanical prosthesis necessitates lifelong anti-coagulant treatments to prevent thrombosis. Such prosthesis is the bi-leaflet valve given in the Fig. 4-C. 


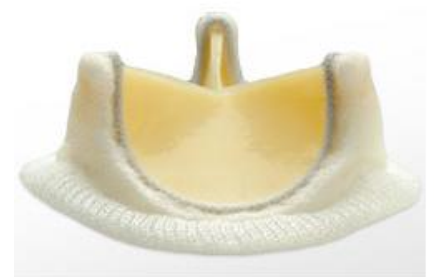

A

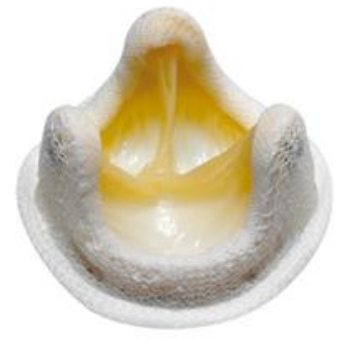

B

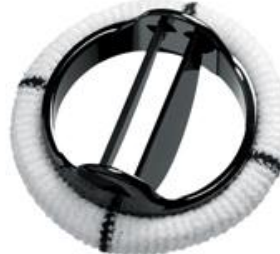

C

Fig.4 AVR prostheses; A -face view of bioprosthesis; B -upper view of bioprosthesis; C - bi leaflet-mechanical

The advantages of AVR are that the surgeon has total control over the tools, calcifications and position of implantation of the prosthesis. Additionally, this treatment is well documented and reliable as it has a long history of practice[20][21]. The burden on the patient's body and potential severe postoperative complications in elderly and often frail patients are the main weaknesses of this treatment. Thus, it is estimated that one third of patients cannot undergo this treatment because of high-risk comorbidities [10].

\section{Socio-economic impact}

The growth of calcifications is a relatively slow process and requires years to become life-threatening. Except for patients with bicuspid valves, it is usually elderly patients over 70 years of age who are concerned by AS. This is precisely the reason why AVR is not sufficient to face this disease. Elderly patients may suffer comorbidities and thus be exposed to high risks during open-heart surgeries. They would then require lengthy recovery times and follow-ups, inducing further costs for the hospital facilities. The cost of AVR intervention is around $\$ 26,900$ [22], however, the total cost of the treatment includes the hospitalization following the surgery. Therefore, the cost increases significantly for high-risk patients: from $\$ 106,277$ (for non-high risk) to $\$ 144,183$ over the course of 5 years, according to M. Clark et al.[23].

The increase of life expectancy also increases the prevalence of this disease in the general population [24][25]. As the proportion of elderly population steadily increases, the number of patients is expected to increase to 1.4 million patients in North America by 2050[26]. Indeed, the authors applied the estimated prevalence of AS in elder patient population and applied it to prediction of the population evolution. Thus, it is crucial to find new solutions to treat the oncoming increase of patients more efficiently.It is estimated that 67,500 AVR were performed in 2010 in the United States [23]. A statistical study estimated that the number of severe symptomatic AS amounted to 540,000 in North America in 2013[26].

\subsection{What exactly is TAVI?}

A recent alternative to the AVR is the minimally invasive TAVI, Transcatheter Aortic Valve Implantation, sometimes called PAVR, Percutaneous Aortic Valve Replacement. Rather than removing the calcified valve, the goal of TAVI is to deposit a prosthesis (TAV) over the diseased leaflets. Examples of TAV are displayed in Fig.4. In order to deliver it onto the impaired valve, the prosthesis is moved through the artery. The prosthesis is crimped in a catheter to fit into the artery, hence the term Transcatheter. Thus, the procedure rests upon complex high-technology prosthesis which can change size. The two most popular models are displayed in Fig.5. Thorough review of new-generation prosthesis can be found in [27]. 


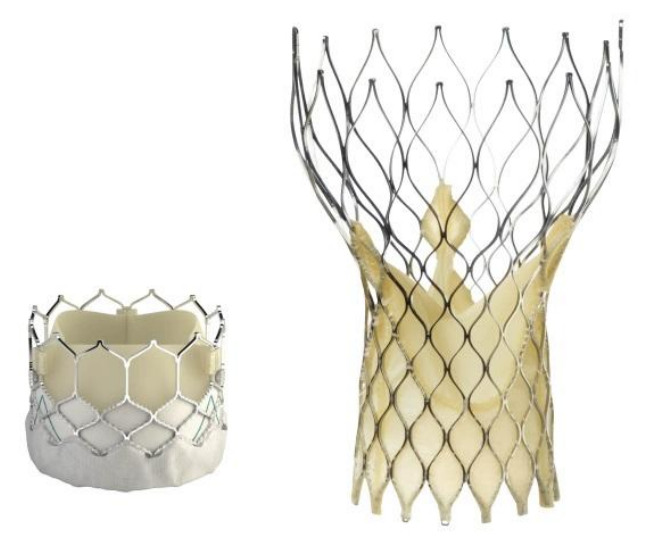

Fig.5 TAV prostheses: left is SAPIEN (Edwards Lifesciences ${ }^{\mathrm{TM}}$ ); right is CoreValve (Medtronic ${ }^{\mathrm{TM}}$ )

TAVI can be used to treat inoperable patients, i.e. patients with chest malformation, repeated open-chest surgeries or serious underlying illness. For now, rather than directly competing with each other, both procedures are complementary, with their own strengths and weaknesses. To date, TAV durability is not well documented with only a few reports with a follow-up to 5 years post procedure. The PARTNER trial[2]showed that TAVI was superior to classic medical treatment and non-inferior to AVR for its 1-year all-cause mortality primary endpoint and the more recent CoreValve US PIVOTAL trial that enrolled patients at slightly lower risk, although still considered high risk, even demonstrated the superiority of TAVI over AVR for the same endpoint[1]. Currently, TAVI is only recommended for inoperable or high-risk patients, as assessed by a "Heart Team" including interventional and non-interventional cardiologists, cardiac surgeons, anesthesiologists, geriatricians, etc. Nonetheless, TAVI offers room for improvement. Better reliability of TAVI would broaden the eligible population, lessen the burden on patients and potentially result in a lower financial cost in the long run. In order to observe the full scope of the hurdles encountered by TAVI, the following parts will describe the procedure. This will help with understanding the complications that can arise from TAVI.

\section{Setting up the guidewire}

The procedure involves steering tools through sinuous arteries to the valve location. Once a stiff guidewire is set up into the left ventricle, the tools are easily brought on a catheter gliding over the guidewire. The guidewires are preferably inserted through the femoral artery but TAVI may be performed by sub-clavian, carotid, direct aortic and transapical approach, as seen on Fig.6. There is a recent increase of prosthesis models, some of them are specialized for a specific type of approaches, such as Engager (Medtronic ${ }^{\mathrm{TM}}$ ) which is specifically designed for transapical approach[27].

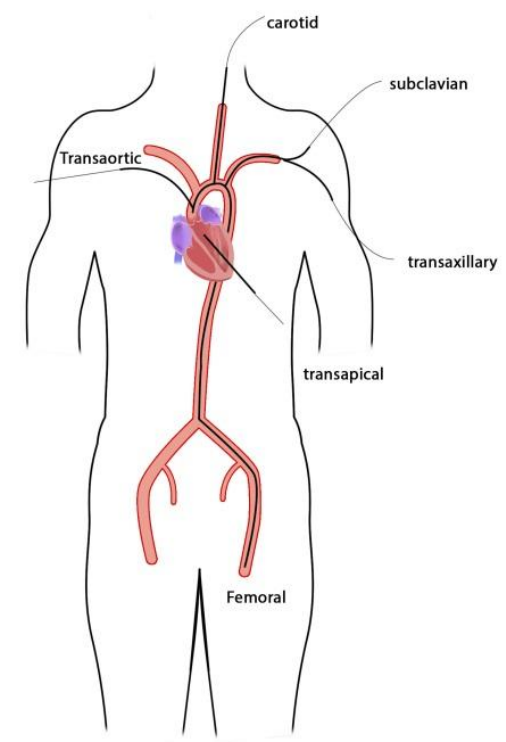

Fig.6 Map of vascular access for TAVI 


\section{Predilatation}

Once the stiff guidewire is inserted into the left ventricle, it is possible to deploy the prosthesis. However in some cases, the calcified aortic valve does not allow the prosthesis passage. In order to force the valve opening, a predilatation is usually performed. This step is called aortic valvuloplasty or balloon valvuloplasty. A balloon is brought to the calcified valve and expanded as shown in Fig.7.

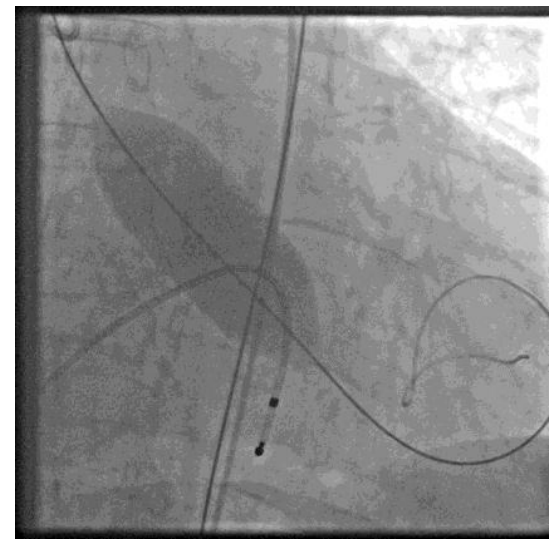

Fig.7 X-ray fluoroscopy of a patient undergoing predilatation

The pressure at the heart output is so high that deploying a balloon without precaution may tear the heart valve and damage the aorta. Hence, it is necessary to suspend the blood flow with "Burst stimulation". The heart is stimulated at a very high rate by a temporary pacemaker introduced in the right ventricle through the femoral vein. The heart twitches uncoordinatedly without pumping blood, allowing balloon deployment.

\section{Prosthesis Deployment}

The two most popular TAVI prostheses worldwide are SAPIEN (Edwards Sapien, Edwards Lifesciences, Irvine, CA, USA) and CoreValve (CoreValve, Medtronic, Minneapolis, MN, USA). These devices are displayed in Fig.5. Those two prostheses have different deployment mechanisms. SAPIEN is balloon expandable, meaning a balloon deployment is necessary to implant it. Another burst stimulation is required during this step. The deployment is fast but the position cannot be corrected once it begins. CoreValve is self-expandable, it adopts its final shape as it is released from the sheath. The medical team releases CoreValve progressively $(10 \%, 25 \%$, $50 \%$, etc.) and continuously adjusts its position during the deployment which may still be challenging because of difficulties to predict the final position of the prosthesis once deployed.

Whichever prosthesis is chosen, it is brought to the middle of the native valve along the guidewire. When the medical team is ready, the prosthesis is unsheathed and carefully deployed. While this procedure sounds promising, some challenges remain. Its performance is still uncertaincompared to AVR for non-high risk patient, while its current operation cost is far higher[22]. Complications following TAVI exist and increase the mortality rate. It is critical for the development of TAVI that the cost of the devices decreases and that its complications are addressed.

\subsection{TAVI Challenges}

Thanks to the efforts of Cribier et al.[4],the first TAVI was executed in 2002. However, 13 years of evolution in procedures, prosthesis, and delivering tools are too limited to completely erase complications. This part lists the main complications encountered in the TAVI procedure reported[7].

\section{Positional shift}

AVR allows total control of the tools, the implantation site and the anchoring of the prosthesis by the surgeon. In the opposite case, tools in TAVI are remotely inserted in a way that offers little control for the operator. Concretely, the AVR surgeon can precisely cut the aorta to position the prosthesis, while TAVI only allows for 
the length of insertion for the prosthesis deployment. As a result, the prosthesis can shift during its implantation. An experimental study showed the SAPIEN shift longitudinally during deployment[28]. Although minor for most cases, a significant shift can unexpectedly occur and lead to complications [29]. It must be noted that different models of stent induce different shifts. It was observed that SAPIEN 3 and the former version SAPIEN XT do not behave the same way[30].

Moreover, the angle of deployment and the shift between the center of the aortic valve and the prosthesis prior to implantation are difficult to control. Fig. 8 shows a TAV in a slanted starting configuration for deployment. It may be difficult for inexperienced teams to accurately predict the outcome of deployment. Hence, one of the major issues of TAVI is the positioning reliability of the prosthesis inside the native valve. Because of an unreliable control of the implantation, this can lead to a variety of different complications.

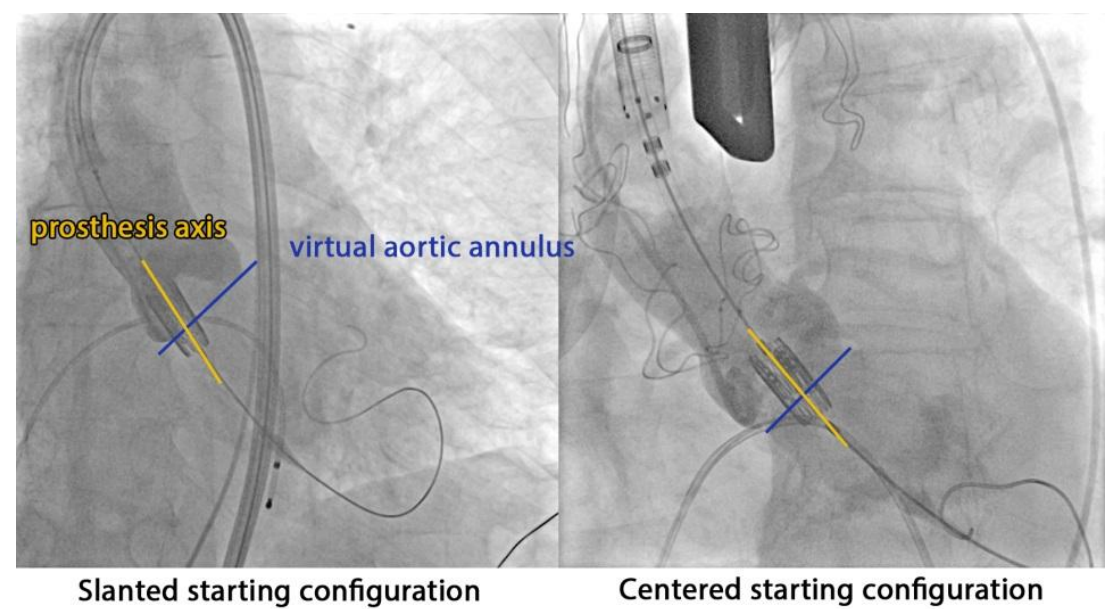

Fig.8 Misaligned starting position of TAV for the deployment in two different patients receiving a SAPIENTM

\section{Coronary occlusion \& Migration}

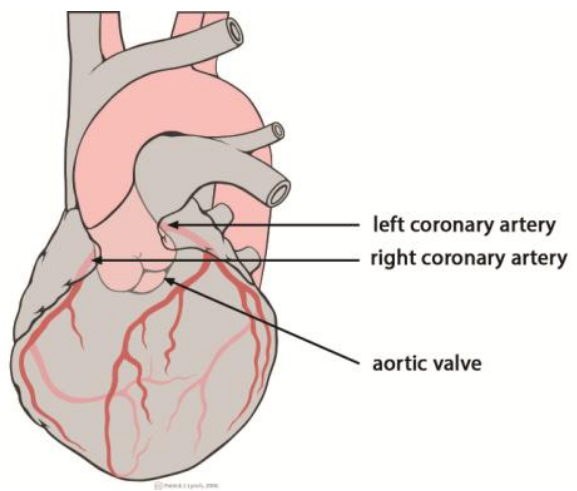

Fig.9 Heart with highlighted aorta and coronary arteries (illustration from Patrick J. Lynch)

Coronary arteries supply the heart with blood. They begin in the aorta, few millimeters, around $12 \mathrm{~mm}$ on average, above the valve as seen in Fig.9[31]. A misplaced prosthesis may block the coronary, which will lead to myocardial infarction. Coronary occlusion also occurs when the calcified native leaflet shifts towards the coronary artery [32] or when a calcification migrates into the coronary [33]. Migration of TAV can also happen due to misplacement, either into the aorta if the prosthesis is deployed too high, or into the left ventricle when excessively low [29].

\section{Mitral valve injury}


The mitral valve is right beside the aortic valve, c.f. Fig.2. It has two leaflets which are linked to papillary muscles on the heart wall. The "super stiff" guidewire placed in the ventricle may injure the mitral valve or its muscles. Low prosthesis may also hinder the mitral valve, and cause serious degradation to it [7].

\section{Atrioventricular block}

A nerve network is spread through the heart, allowing polarization of the heart muscle and triggering the heart contraction. If the prosthesis is too low, it may lead to atrioventricular block, which is a disturbance of the nerve network, and induce conduction abnormalities. In this case, the patient needs a permanent pacemaker. This complication happens more often in TAVI than in AVR and three time more often in CoreValve than in SAPIEN prosthesis[34]. This is an additional cost because this complication can appear up to 6 days after the intervention, prolonging the duration of hospitalization for monitoring.

\section{Prosthesis mismatch}

AS is a decrease of the opening valve area. The goal of TAVI is to restore the valve area. However, a small enlargement of the opening area may not bring significant benefit to the patient. Sometimes, the overall impact of the TAVI can be negative instead of alleviating the patient's situation. Those situations are referred as prosthesis mismatch. It is a significant problem when implanting a new prosthesis inside an already existing one (valve-in-valve maneuver) or a bicuspid valve [35]. The prosthesis functional area will be smaller than the maximum aortic valve area of the anatomy. Also, the prosthesis may not be fully deployed inside bicuspid valves. Otherwise, mismatch still remains a rare occurrence compared to classic surgery[36][37]. Prosthesis mismatch can also occur when the chosen prosthesis is undersized. However, an oversized prosthesis may result in other problems, e.g. aortic injury. Hence, the expertise of the medical team is crucial to determine the best compromise limiting the risk of complications.

\section{Aortic injury}

The aortic root containing the valve may rupture following the implantation of the prosthesis. This complication is particularly difficult to study because of its low frequency $(\sim 1 \%)$ and many types of rupture can arise [38]. Aggressive oversizing of the prosthesis was said to be related to this [6]. However, Hayashida et al.[39] suggested that the calcification layout on the aortic root is a strong reason for the aortic rupture[39]. Indeed, dislodged calcification may push vulnerable area of the aortic root.

\section{Leaks}

Paravalvular leaks remain a big hurdle in TAVI. They are less likely to occur during AVR. Leaks cause regurgitation which burdens the heart and may be correlated with long term prognosis and late mortality [40]. In engineering concepts, leaks contribute to significant energy loss in diastole [5][35]. Much like the previous complications, paravalvular leaks may be related to an inadequate sizing of the prosthesis, as oversized prostheses are said to reduce leaks [7]. The stent must adapt to the shape of the aorta wall. This depends significantly on the calcification scattered on the native valve. As the leaflets are designed to open and close correctly when totally circular, the stent must also be as round as possible to prevent a central leak [41].

There are different types of leaks, which are represented in Fig.10[42]. Transvalvular leaks come from an insufficient coaptation of the prosthesis leaflets. In other words, the leaflets do not seal the valve because gaps appear between the leaflets. It may happen when the deployed stent is not circular enough [43]. Paravalvular leaks appear from the gaps between the stent and the aortic wall. Lastly, supra-skirtal leaks occur in a similar way as paravalvular leaks. A skirt is sewn on the stent frame of the prosthesis to seal the gap between the leaflets and the stent. However, if the prosthesis is placed too low, the skirt does not fulfill its function. 


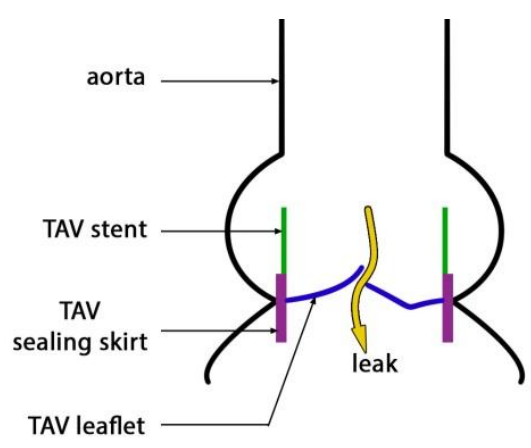

Transvalvular

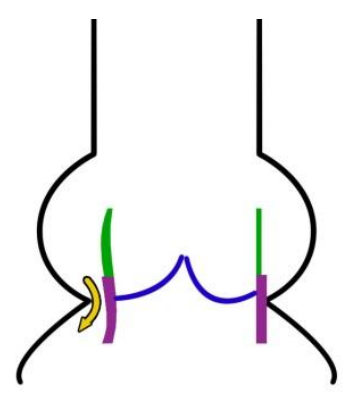

Paravalvular

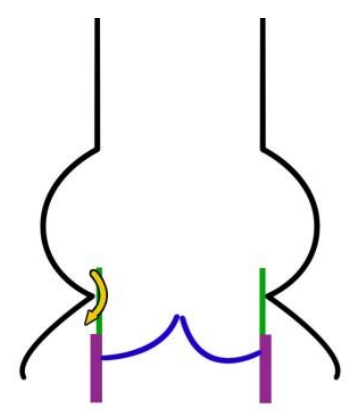

Supra-skirtal

Fig.10 Side section of a leaking TAV; left, transvalvular leak; middle, paravalvular leak; right, supra-skirtal leak [42]

\section{Calcification migration}

Embolic stroke is one of the main concerns of TAVI. During the insertion of delivery tools, the thick catheters may dislodge calcification from the aorta. Besides this, during the balloon dilatation or prosthesis deployment, the native valves are crushed and will release calcific debris which may migrate to the brain [44]. Hopefully, new devices such as embolic filters may reduce these complications [45]. Claret Medical's device, Sentinel, has received approval for the American market. Studies to evaluate its performance are still ongoing.

\section{Financial challenge}

TAVI has quickly been adopted across 40 countries. It is estimated that over 50,000 TAVI procedures had been performed since 2002 [46]. However, the current market of TAVI prosthesis is extremely limited. The few available models are costly. Currently, the performance of TAVI does not justify the healthcare expenditure for non-high risk patients [22]. Lowering the cost and improving the performance of TAVI are necessary steps to broaden its use.

Current medical research is focused on preventing those complications. Patient-specific simulation is a very relevant path to explore in order to predict the complications. The next part reviews the TAVI finite-element models that have been created so far and how they can help clinical workflow.

\section{State of the art}

\subsection{Beneficial impact of patient-specific simulations}

TAVI has yet to overcome the problems described in the previous section. It has a strong potential because it can treat a broader population than AVR can. Also, the minimally-invasive procedure itself leaves the patient in a better condition than patients recovering from thoracotomy. However, TAVI cannot guarantee total relief of aortic valve dysfunction. In such cases, the degradation of the patient's condition does not stop and leads to further hospitalization. We can distinguish two ways to overcome complications. One way would be the improvement of the TAVI procedure itself. This can be achieved through various ways such as the development of prostheses, delivery tools, tracking tools, and imaging devices.

Some anatomies are more prone to complications than others. Therefore, another aspect to improve on is the planning and patient selection criteria in order to reject those with high risk anatomies. Accurate selection will help to make the best out of TAVI by treating patients who require minimally invasive intervention while avoiding high risk patients. Thanks to the continuous medical research in TAVI, the sources of complications are better understood. In vitro, in vivo and numerical simulation clarified many phenomena [47]. In practice, those problems are very difficult to avoid, as their mechanisms cannot be fully handled with current decision support tools. Some patients who seem perfectly fine to receive TAVI turn out to be problematic cases, e.g. aortic rupture [39]. In other words, despite a better understanding of the phenomena, complications still remain highly complex problems. Thus, the knowledge of complications cannot be easily generalized. It is of utmost 
importance to study case-by-case complication risk. The medical team handling the surgery needs strong expertise of TAVI to ensure success. Large differences were reported between inexperienced, beginning medical teams in comparison to experienced ones [48]. Moreover, different models of prostheses behave differently. Medical teams experienced with one TAV model may not easily use another one. For all those reasons, medical teams can benefit from quantitative tools to aid the surgical planning, assessing and comparing AVR and TAVI postoperative performance.

Different approaches are available to predict risk. The statistical risk assessment can prove to be a helpful decisional tool as it can provide risk scores to predict failure of intervention. Statistical risk models are developed using post-data results of previous intervention. For instance, Euroscore is aninternationally used risk model to evaluate the risk of death after heart surgery, and uses a manageable amount of parameters such as age, gender, comorbidities, etc. Risk scores can also be applied to TAVI [49]. In the end, risk scores provide limited information about the type of complication and how it may be solved. Though risk scores are an asset to spread the use of TAVI, it does not invite development in complication management. Moreover, statistical models are restricted in the amount of input parameters, and as previously said, complications are difficult to generalize. Another drawback is the evolution of tools and prosthesis type. It is safe to assume that the quality of prosthesis models may impact the risk. Then, new models cannot benefit from statistical risk assessment since post-op data would be non-existent.

On the other hand, numerical simulations take into account intricate input data and can offer a better grasp of complications. Thus, this method can provide finer risk assessment than statistical risk models and better insight on the complication mechanisms.

\subsection{Chronology of TAVI simulation}

Papers concerning TAVI and aortic valve simulation were primarily retrieved from PubMed and Google Scholar, using the keywords: Transcatheter Aortic Valve Implantation simulation, Finite Element Aortic Valve, Fluidstructure Aortic Valve. Additionally, backward and forward snowballing was performed to extend the bibliography. Some of the following studies are not patient-specific. However, those models of simulation may be adapted to patient-specific geometries to design a patient-specific planning procedure. Papers closely concerning TAVI are reported in tab.1.

We can observe an increase of numerical simulation studies concerning TAVI during the last decade. We found that the first simulation study concerning TAVI prosthesis was made by Dwyer et al. (2009) to characterize the blood ejection force that can migrate the prosthesis[50]. However, the first study using patient specific data for TAVI was proposed by Sirois et al. (2011)[8]. Though numerical study of TAVI is recent, the use of simulation had already been developed in numerous applications. For instance, studies about kinematics of native aortic valve greatly helped TAVI studies. Some of the relevant studies remotely concerning TAVI are reported in tab.2.

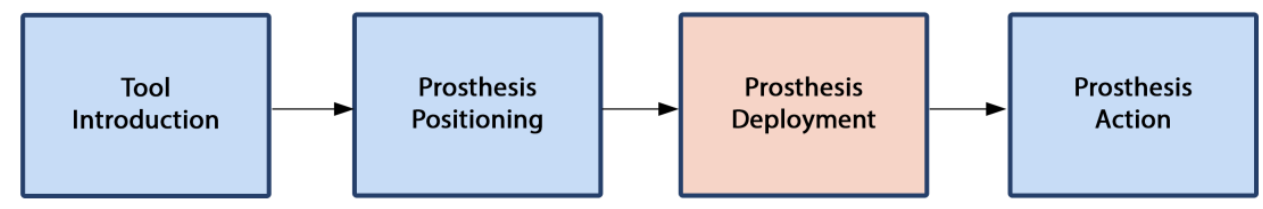

Fig.11 Different stage of TAVI procedure

TAVI simulation studies usually concern only one step of the procedure. Fig. 11 summarizes the main steps of TAVI. As the previous table reports it, most of the papers focus on the prosthesis deployment step. This is a critical step because it predicts the final prosthesis configuration. Indeed, most complications are dependent on how and where the prosthesis is anchored in the aortic root. A realistic deployment simulation should take into account input data such as prosthesis configuration prior to deployment. Anticipation of the prosthesis behavior during this critical step is greatly beneficial for medical teams. Currently, they have to choose the starting position of the deployment without any certitude regarding how the prosthesis will behave during implantation. However, no simulation study has been done yet on the insertion of tools and prosthesis starting configurations.

Even though simulations are not advanced enough to predict where the prosthesis will land depending on the starting position yet, they can provide invaluable insight on possible outcomes and optimal prosthesis sizing. Additionally, final prosthesis configuration is a preliminary input for the following step, which consists in simulating the prosthesis function in the patient anatomy. The goal of the next step is the hemodynamic 
assessment for the performance of the valve. This can help choosing the best procedure between TAVI and AVR. It would also be possible to find the optimal final position of the prosthesis. Indeed, Groves et al. [62] showed that the position of the prosthesis impacts the quality of hemodynamics such as blood velocity and coronary perfusion[62].

The deployment of balloon-expandable TAV is mainly a structural problem, where blood flow can be neglected thanks to burst stimulation and the speed of the deployment. As a result, published studies largely exploit Finite Element Method (FE) in order to simulate the prosthesis' expansion. On the other hand, neglecting blood flow is a less obvious choice for self-expanding TAV, as its deployment is slow and the TAV is liable to slightly migrate with blood pressure. In this case, methods encompassing blood flowmay be considered. For instance, CFD simulation (Computational Fluid Dynamic) can simulate the blood flow. It seems that there is a strong interaction between the blood and valve as it pushes the leaflets. Therefore, a strong coupling is needed between the fluid aspect and structural aspect. A relevant approach is FSI simulation (Fluid-Structure Interaction).Moreover, the complex mechanical behavior of a self-expanding stent is an additional challenge for researchers. Very few studies concern self-expanding TAV for now, but more is expected to come. Indeed, a large proportion of new prosthesis models are using self-expandable technology : CENTERA, Acurate, Jena Valve, Portico, UCL TAV, Foldavalve, etc [63][27].

When prosthesis deployment is successfully simulated, studies attempt to extract useful criteria in order to estimate the prosthesis performance. Simple criteria can be assumed from the deployment data, e.g. stresses, strains and shape of the stent and leaflets. However, they remain too limited to reliably predict performance. As a result, some papers tackle the next step, following the deployment step. Sirois et al. [8]were the first to suggest a CFD simulation after FE deployment to characterize the blood flow. Auricchio et al.[57] performed another step to close the valve through FE simulation[57]. In both studies, the movement of the leaflet was obtained through FE simulation and originated from uniform pressure upon the leaflets, instead of the action of the blood. This type of model is called "dry" model as it replaces fluid by prescribed pressure.

However, FE simulations may fail to reproduce the complete in vivo behavior and thus provide inaccurate data. A more exhaustive type of simulation would be Fluid-Structure Interaction (FSI) as it couples fluid mechanics to structural analysis. FSI techniques are still maturing in order to study healthy native aortic valve behavior, but numerous results and hypothesis can be applied again to TAVI simulations since those healthy valve models are very advanced. Results from those studies that can be applied to TAVI are reported in tab.2.

FSI has not been fully implemented in the context of TAVI yet. One exception is the study by Kemp et al. [56], which studies a custom-designed TAV prosthesis. Even though careful consideration of the fluid through CFD or FSI is a reasonable idea, current models might be insufficient to provide reliable data, as Sotiropoulos et al. and Stewart et al. pointed out[64][65]. As FSI progresses, we can expect FSI studies of TAVI performance to appear. Still, it is not clear whether the FSI gain in accuracy for hemodynamic assessment can justify the computational cost, but FSI is used more and morein applications such as mechanical aortic valve prosthesis [66].

\section{Method of simulation}

In this section, various aspects needed to define simulations are reviewed. Main points of those different aspects have their dedicated part: meshing the valve, mechanical properties of the tissues and boundary condition. For readers seeking complementary points of view on heart valve simulation, reviews from W. Sun et al., G. Marom et al., Votta et al., Tseng et al. can be particularly useful[89][90][66][47].

\subsection{Geometry}

\section{Imaging challenges}

Simulation studies have shown that geometry can significantly impact the results. In particular, it was found that asymmetry in geometrical configuration of the leaflet impacts the leaflet stress, and consequently, the valve durability [68]. It has been shown in numerous studies that the sinus of Valsalva also influences stress distribution for both the aortic wall and leaflets [69][77][79]. In addition, the aortic wall deformation significantly participates in the valve opening [70][71]. All this evidence concurs on the importance of accurate 
geometry representation of both the aortic wall and leaflets. However, accurate imaging of the leaflet and aortic wall is challenging because of its motion throughout the cardiac cycle. Therefore, imaging techniques and image processing knowledge play a large role in the extraction of patient-specific anatomy. Indeed, image processing is required to extract relevant elements from patient anatomy. For instance, the pulmonary artery usually overlaps with the aorta. This can disturb the extracted valve geometry.

Several imaging techniques are available in clinical practice, such as echocardiography or magnetic resonance imaging (MRI). Currently, the main technique being used to obtain 3D geometry for TAVI simulation is the multi-slice computed tomography (MSCT or CT). On the other hand, FSI simulation usually prefers MRI, as it may also provide fluid data (4D MRI flow imaging). Even though echocardiography is widely used clinically to assess valvulopathy, 3D echocardiography has poor spatial resolution and is not sufficient for geometrical reconstruction alone.

Before a TAVI, patients usually undergo a CT scan for the planning of procedure. Because classic CT scans are not instantaneous, they fail to grasp the quick movement of the leaflets. However, "Gated CT scans" are synchronized with the ECG (electrical heart activity). Those scans allow accurate representation of the leaflets at a specific phase of the cardiac cycle, provided the patient ECG is regular. Those synchronized scans allow finer 3D reconstruction of the anatomical architecture of the patient. However, the drawback of CT scans is the radiation exposure and nephrotoxic contrast media injection in the patient.

\section{Aortic wall \& native leaflet reconstruction}

Numerical simulations of TAVI opted for CT scans, but there is no agreement on the extraction method. We report numerous different software: VTK, Mimics (Materialise, Leuven, Belgium), Avizo (VSG, Burlington, MA), ITKsnap etc. Tab.3 reports in the second column the image processing software used in various studies. It is difficult to automatically extract the fine details of anatomy, such as leaflets, even though synchronized CT scans offer good quality. Therefore, most studies manually traced those parts, or used geometric reconstruction from landmarks. Capelli et al. [51] and Wang et al. [58] extracted the native leaflets directly from CT. However, Capelli et al.[51]mentioned the difficulties and the efforts required to extract them. Indeed, Osirix and Avizo are both general segmentation software, but require expertise from the operator. This is why imaging processing techniques are crucial to introduce patient-specific simulation in the clinical field as an easy-to-use planning tool.

Studies used various phases of the cardiac cycle, usually either at peak systole or peak diastole, when the motion of the leaflet is minimal. Capelli et al. [51] and Wang et al. [52]reconstructed the leaflet in its systole phase[52]. Wang et al. [58] used diastole instead. It is worth noting that Morganti et al. [59]reconstructed the native healthy leaflet from manual landmarks, and projected calcifications upon it. Indeed, at the start of the simulated deployment, the native leaflets were completely open. However, it was open well beyond the case of a severe aortic stenosis. The starting configuration should be stress-free, meaning that the effort to push the calcified leaflets open may have been underestimated.

After extraction of the geometry, it is necessary to produce a proper mesh for calculation. Other software is usually needed. This step can either be made on dedicated meshers like ICEM CFD (Ansys, Inc., Canonsburg, PA, USA) and HyperMesh (Altair Engineering, Inc., MI) or on solver preprocessors such as Abaqus (Simulia, Dassault Systems, Providence, RI, USA). Aortic wall and calcification are often meshed with tetrahedral elements while leaflets are usually meshed with quadrilateral shell elements with reduced integration.

\section{Zero-pressure issue}

In simulations, the initial input geometry of the model should often be in a stress-free state. However, it is important to keep in mind that the scanned anatomy is physiologically loaded, as the artery bears the systemic arterial pressure and other loads. Therefore, the scanned geometry of the patient taken as such in the simulation would be inaccurate, because this geometry is actually the result of loadings while the simulation model should consider it as unloaded. Some studies transformed scanned geometry to find the state of the valve without blood pressure. This state is often referred as the "no-load" state or "zero-pressure" state. This state can be achieved by excising the aortic valve out from the subject.

Some FE studies suggested exploiting the zero-pressure state[52][81][82]. Wanget al.[52]proposed a straightforward method to determine the zero-pressure state. Experimentation has been made to determine the 
relationship between the aorta diameter and blood pressure. Labrosse et al. [82] used a mathematical model for the geometry of the aortic valve and dimensions of the unpressurized aortic valve provided by prior experimental studies [91]. Conti et al. [81] used a mathematical model as well. However, the dimensions of the model were identified from their MRI data. The mesh from MRI data underwent an iterative algorithm to identify the zeropressure dimensions.

However, arteries and valves may also be subject to complex internal stress. It was found that radially cutting arteries will make them spring open[92]. Such configuration is referred as the "no-stress" state. W. Huang showed that the inner wall of arteries is in compression and that the outer wall is in tension[93]. Zhao et al. showed how the no-stress state impacted simulations data[94]. X. Huang et al. suggested a method to compute the no-stress state, proving the feasibility of computing no-stress configurations[95]. However, simulation studies concerning TAVI have not exploited no-stress configuration yet.

\section{Calcifications}

Another geometrical detail that is difficult to grasp, yet which has crucial importance, is the calcification. Synchronized CT-scan may provide a precise layout of the calcifications. There are different possibilities to represent them in the mesh. Capelli, Morganti and Wang modeled calcifications as "zones" projected onto the leaflet, c.f. Fig.12 (left)[51][59][52]. The reconstructed native leaflet geometry is overlapped with CT-scan containing calcification data as described in [59]. It is assumed that the calcifications intersect the valve geometry and give the positions of calcific shell elements. These calcified zones were thicker compared to a healthy leaflet, as if calcification grew from both sides of the leaflet. In other words, a calcified zone encompassed both the normal leaflet layer and its calcifications. Calcifications on the aortic wall were ignored in the study[51], however they might be relevant as the aortic wall has been shown to participate to valve opening [70]. Although Wang et al.used such equivalent zones (leaflet+calcification) in their first study [52], theyconsidered the calcifications as separate from leaflet in their next study [58].Indeed,they hypothesized that calcification did not have fixed thickness and grew on one side of the leaflet, c.f. fig.12 (right). Also, Wanget al. projected calcifications on the aorta. Similar method was also previously applied by Russ et al, where segmented calcification elements were tied to the closest element by constraint [54].
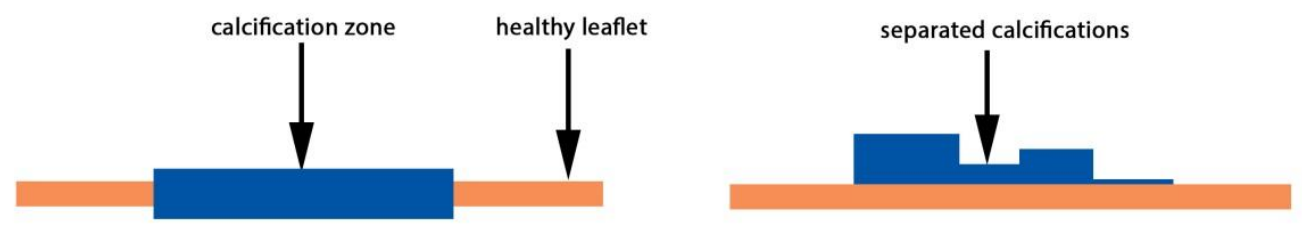

Fig.12 Calcification models; left is used in most studies; right is used by Russ et al. and Wang et al. [54][58]

The level of description of calcified aortic valve undoubtedly requires further study. Another question about anatomy is how much of the surrounding tissues should be modeled. Indeed, the aortic valve is connected to the ventricle below, and connected to the aortic artery above. Wang et al. [52]suggested including a part of the myocardium into the simulation. However, no subsequent studies followed this recommendation.

\section{TAVI tools}

Depending on the simulated step (tool insertion, deployment or post-deployment) and the hypotheses, different tools should be modeled. Most studies focus only on the deployment stage, which does not require the prosthesis leaflets. All papers reported about TAVI reconstructed at least the prosthesis stent. As it was stated previously, and also reported in Tab.3, most studies focused on the Edwards SAPIEN (Edwards Lifesciences, Irvine, California). As of today, the SAPIEN is the only available balloon-expandable prosthesis.

So far, CoreValve (Medtronic Inc., Minneapolis, Minnesota) stents are included in few studies [53][54][61]. These studies proposed an accurate mathematical model for the geometry. It has been reused by Tzamtzis et al.[55]. Lastly, a generic self-expandable stent has been designed by Gunning et al.[60]. This new model was motivated by the fact that many new commercial devices use this mechanism. 
In both TAV prostheses, leaflets were sometimes modeled. The usual approach is defining the leaflet through a mathematical model, and morphing it to adapt to the stent [57].

In the case of a balloon-expandable stent, the balloon should be modeled as well. In most cases, it is modeled as a simple rigid cylinder whose nodes are constrained to expand. There are some exceptions, however, as Auricchio et al. and Wang et al. modeled the balloon with a realistic geometry[57][58].

\section{Summary}

While zero-pressure and no-stress states might be important in Abdominal Aortic Aneurysm for accurate prediction of aortic rupture [96], no study has proven its importance in the context of TAVI yet. Grande-Allen (2000) suggested the hypothesis that the residual stress was negligible in comparison with the valve and root stresses, and so far no study has challenged it[69]. Another notable point of the geometry section is the lack of an automated method to extract patient-specific geometry. Leaflet and valve extraction is an image processing technique and an image processing question that has no definite answer yet. Because of the small size and the transient nature of those details, they are difficult to extract from scans. Efforts are currently made to automatize the extraction of patient-specific geometries[97]. Some studies explore the use of parametric models whose dimensions are fitted with image recordings. For instance, Haj-Ali et al. \&Rankin et al. suggested various parametric models[98][99]. Zheng et al. \& Pouch et al. elaborated methods to extract leaflets[100][101]. In the study from Mansi et al.[102], an automated method can accurately extract the mitral valve.The spread of these fully automated tools is a necessary step: Not only would it make patient-specific simulations easy-to-use for medical teams, but it could also help exploit large patient data sets for validation studies. So far, no study has used such tools yet, but we can expect new studies featuring new methods in the future. Additionally, the use of patient-specific simulation in the clinical framework raises the issue of computational time and model complexity. The complexity of the model should not induce an impractical, long duration of computation in order to meet the clinical needs. However, the current stage of development of numerical simulation is not advanced enough to tackle this issue.

\subsection{Mechanical properties}

Detailing constitutive equations of each material model is beyond the scope of the present review article. Readers are referred to the review articles for a general description of the different material models widely used in simulations[90][89]. A short explanation is given in the following section.

\section{Aorta \& leaflets}

We can observe different types of constitutive mechanical models. Linear elasticity (LE) is a model where stresses and strains are linearly related. A typical stress-strain curve is straight as shown in Fig.13 left. Linear elasto-plasticity (EP) is a model where the material can have permanent deformations. Tab.4 reports the different material models used for the aorta, leaflet, calcifications and prosthesis in the studies related to TAVI simulation. Concerning non-linear elastic behavior, several models are available. Hyperelasticity (HE) is a more complex model where the stress is related to strain energy density. It is often used to model non-linear elastic stress-strain responses, as shown in Fig.13 right.Another class of models used to describe soft biological tissues are the models based on the law of mixture (composite or mixture theory). Those multi-layered models take into account the contribution of all the structural constituents in the mechanical behavior of the material (elastic fibers, smooth muscle cells, fibrillar collagen). Those models are commonly applied in cardiovascular mechanics [103][104][105][106]. 


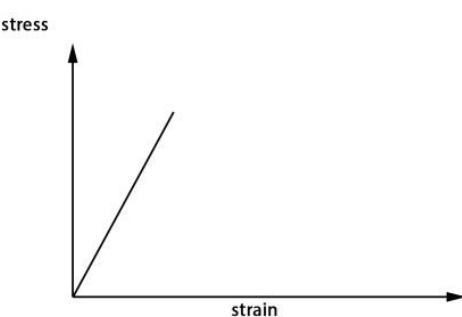

Linear elastic behavior

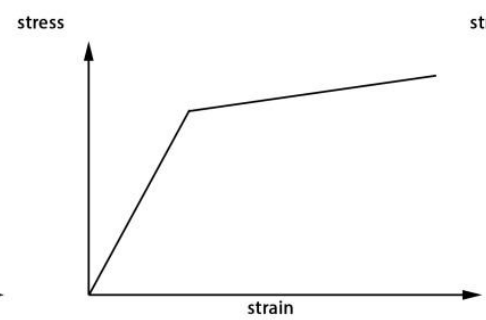

Linear elastic-plastic behavior

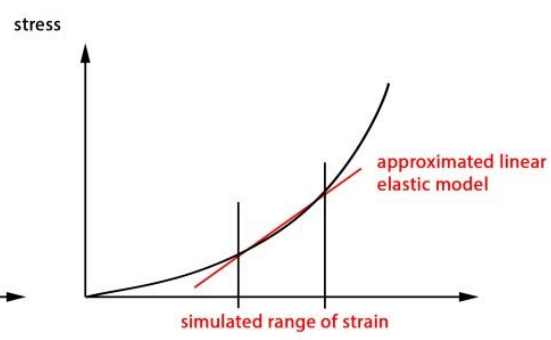

Non-linear elastic behavior

Fig.13 Mechanical models used in numerical simulations for TAVI

All the studies agree that anisotropic and hyperelastic models are required for biological soft tissues in TAVI simulations. Russ et al. compared rigid, linear-elastic and hyper-elastic isotropic models in a special deployment simulation[54]. Despite the fact that the hyperelastic model is supposed to have the highest accuracy, the difference found with a linearized elastic model seems negligible given the conditions of the deployment $5.5 \%$ deformation error from hyper-elastic versus $5.8 \%$ for linear-elastic). A simplifying hypothesis can reasonably be adopted. Because aortic root does not significantly deform during implantation, linearization of the material properties seems viable. Proper linearization requires finding the adequate level of loading on the aorta during implantation and using the corresponding Young's modulus, as seen in Fig.13 (right).

The use of hyperelastic laws may emphasize the sensitivity of simulations to the lack of zero-pressure state. Indeed, hyperelastic model of soft tissues shows a small stiffness at very low strain (horizontal slope) and high stiffness at higher strain (steeper slope). Therefore the mechanical response of hyperelastic material changes significantly depending on its level of strain. However, we have seen in the previous section that the geometry, taken as it is, has an initial loading in the patient. This load induces a pre-strain that increases the stiffness of the aortic wall, if the physiological configuration is erroneously used as a zero-pressure configuration. Surprisingly, among the papers using hyperelastic constitutive models for the aortic wall, only Wang et al. [52] explicitly computed the zero-pressure state of the aortic valve. Then again, other aspects of simulation models that need better adjustment may have a stronger impact on the simulation. Therefore, the development of zero-pressure models in the context of TAVI might not have the highest priority so far.

The TAVI simulations that take the native leaflets into account often use the same model for both the aortic wall and the leaflets. In opposition, it is common in FSI studies to use a linear elastic model for the aortic wall and a hyperelastic one for the leaflets. As a matter of fact, biological material models were an important aspect in studies for dynamic analysis of aortic valve behavior. This is understandable given the importance of native leaflets in the latter type of studies, which are precisely focused on the motion of the leaflets. Indeed, some TAVI studies do not even take native leaflets into account. In the case they do, the native leaflets end up tightly crushed by the stent. The anisotropic model appeared relatively late in TAVI studies compared to dynamic aortic valve studies. Auricchio et al. [57]\& Wang et al. [58]are the first TAVI simulations to propose an anisotropic hyperelastic model. The aorta is represented as a composite material including 2 families of fibers [110]. Moreover, a failure criterion based on maximum stress for rupture was implemented.

Meanwhile, concerning studies about the motion of leaflets, De Hart et al. and Driessen $e t$ al. thoroughly tested the fiber-reinforced anisotropic hyperelastic material model for the leaflets[74][114]. Marom et al. studied the impact of assigning different material parameters between the three leaflets[86]. Koch et al. compared various constitutive material models[83]. Four cases were tested: isotropic linear elasticity, transversely linear elasticity, isotropic hyperelasticity and transversely hyperelasticity. The limitation of those studies lies in the fact that a perfectly healthy aortic valve is considered. In the case of patient-specific simulation, the incertitude on the material parameter may be more impactful compared to the type of material model chosen.

\section{Calcifications}

Capelli et al.[51] and Morganti et al. [59]considered calcified zones, the calcified zone material being an equivalent model which encompasses the leaflet and the calcification characteristics. Thus, they used a linear elastic material, stiffer than a healthy leaflet and less stiff than pure calcification. Young's modulus (10 MPa) was chosen according to Loree et al.[115]. Capelli et al.[51]also suggested a method to represent the effect of 
calcification against the opening of the valve. The calcified nodes at the junction between the leaflet and the wall were completely tied. However, a limit on maximum stress induced a rupture of this junction and the leaflet may deform more easily.

Both studies from Wang et al.[52][58] used linear elastic model. The first study used calcified leaflet zones but included a very stiff material model (Young's modulus of $60 \mathrm{GPa}$ ). This choice is based on the study of Ebenstein et al.[108] that reported high elastic modulus from nanoindentation experiments. It seems reasonable that the material model obtained from nanoindentation relates to a relatively 'pure' calcification. However, that choice would seem more appropriate in the second study of Wang et al.[58], where the leaflet and calcifications are separate entities. Instead, Wanget al.[58]used a stiffness (Young's modulus of $12.6 \mathrm{MPa}$ ) based on another study [111].

\section{Prosthesis}

Edward's SAPIEN series are balloon expandable models. The former stents are made in stainless steel. Tzamtzis et al.[55]used a linear elastic-plastic to represent X2 CrNiMo-18-15-13 alloy. However, the latest models (e.g. SAPIEN 3) include a cobalt chromium frame. Morganti et al. [59]used updated mechanical characteristics for the cobalt chromium alloy.

On the other hand, Medtronic's CoreValve series is a self-expanding prosthesis. Its mechanical behavior is very complex, as it depends on its thermo-mechanical history. CoreValve complexity is not popular in patient-specific simulations, since most of them feature the Sapien prosthesis. Still, Russ et al. simulated the deployment of a CoreValve stent[54]. However, the study assigned it a linear elastic-plastic behavior. Tzamtzis et al. [55]made a set of mechanical experiments to determine the mechanical response of CoreValve in a $37^{\circ} \mathrm{C}$ environment. He considered a complex mechanical model for NiTi material, which was developed by Auricchio et al. [116]. Gunning et al. simulated a realistic self-expanding stent deployment[60]. They applied the same material model on a custom-designed stent from the study by Tzamtzis et al.[55].

\section{Friction}

Apart from constitutive material models, it may be necessary to define the friction behavior between the different parts of the model. Indeed, friction plays an essential role in the prosthesis stability, as it counteracts pressure gradient [50]. Tab.5 reports the coefficient of friction used in TAVI simulations. Exceptionally, Morganti (2014) does not assign friction[59]. However, the stent is vertically constrained so that it does not migrate.

It is important to note that leaflets and calcifications are not always taken into account in those studies. It is believed that those can give support to the prosthesis [50]. Therefore, the tuning of friction coefficients by the different studies may come from the need to encompass the effect of the missing calcifications and leaflets over the support.

\section{Summary}

Studies exploit progressively more advanced constitutive material models. Some of them, however, may come with additional costs. For instance, complex models may require more efforts to adjust and more computational time. Also, more realistic models may increase the sensitivity of the simulation to other aspects which were previously neglected. It is suspected that the use of hyperelastic models increases the sensitivity to the initial geometry of the model, which should take into account the zero-pressure state. Studies are needed to clarify this aspect.

Lastly, a hurdle to patient-specific simulation is the identification of the patient specific mechanical characteristics. The mechanical response of the aorta may vary from patient to patient, with different ages and diseases. Invasive measurement of a patient's aortic valve mechanical properties for simulations before TAVI does not seem a viable option. Efforts are made to develop methods to assess in-vivo material properties such as vascular elastography. Wittek et al. \& Flamini et al. proposed a method to assess aorta mechanical properties from 4D ultrasound data[117][118]. The constitutive model parameters of patient-specific arteries can be obtained from inverse FE method and measurement of the artery wall strain from blood pressure changes. However, these methods do not seem applicable to the aortic valve yet. Different degrees of calcification may 
also lead to very variable properties too. Thus, TAVI simulation lacks in the patient-specific material aspect. The choice of material model will remain a challenging question in TAVI simulation.

\subsection{Boundary conditions}

Boundary conditions are an important input in the model to perform reliable simulations. Like geometry of anatomy and mechanical properties of tissues, the complexity of human physiologic conditions does not allow exact representation in the simulations. This is even more evident in patient-specific cases, where a lot of parameters are inaccessible. Therefore, it is often necessary to assume the physiological conditions to define simplified boundary conditions. This aspect of simulation may be the most arbitrary, because there is a very broad range of possibilities to define boundary conditions. Depending on the focus of the simulation study, hypotheses concerning the boundary conditions must be taken accordingly. In the present review article, we will focus on TAV deployment conditions.

\section{Surrounding tissues}

TAVI simulations only consider a small portion of anatomy: the aortic valve. However, the valve is, in reality, connected to surrounding tissues. It is necessary to define how the modeled valve interacts with the external environment that is excluded from the simulation model. In the case of TAVI simulation, there is no consensus about boundary conditions applied on the extremities of the geometry. Capelli et al.[51]constrains every degree of freedom of the nodes along the extremities, fixing in space the ends of the model. Morganti et al.[59]constrains the aorta and the balloon to not move vertically. However nodes can move radially. Wang et al. [52] expands the geometry zone to the myocardium. Only the upper edge of the aorta (distal side) is constrained in all translations. In other words, we observe either totally fixed nodes, or plane-constrained nodes. However, when experimental data are observed, more complex details appear. The same way the arteries bear circumferential pre-stress, they also bear axial pre-stretch [119]. In studies of aortic valve motion, we observe more varied conditions. Labrosse et al. imposed an axial pre-stretch by prescribing axial displacement to the distal edge[82]. So far, TAVI studies neglected the interaction between the aortic wall and the surrounding tissues. Only the extremities of the model were considered, but it must be kept in mind that those interactions may have to be modeled. Sturla et al. suggested to wrap the aortic root with a virtual fully recoverable foam, the external surface of the foam being fixed[87].

\section{Blood flow}

TAVI studies usually concern classical solid FE analysis, so they do not take into consideration the fluid dynamics. The usual approach to model blood interaction is the use of spatially uniform prescribed pressure. The in-vivo aortic wall is constantly loaded with a minimal blood pressure. However, no simulation of TAVI included this pressure. Wang et al. [52]justified the omission of blood pressure by the decrease of blood pressure during rapid pacing (heart burst stimulation) during deployment. The study suggested that pressure decreases from $80-120 \mathrm{mmHg}$ down to $0-20 \mathrm{mmHg}$. Nonetheless, the reported experimental decrease of pressure is smaller than this estimate: from 62-94 $\mathrm{mmHg}$ down to 34-64 $\mathrm{mmHg}$ [120].

In the case that prosthesis action is also studied, it is necessary to model the transvalvular pressure. The usual method is applying a uniform pressure on the surface of the TAV leaflets. Sirois et al.[8] and Auricchio et al. [57] prescribed pressure only on the leaflets to determine the motion of the leaflets and the closed state respectively. The review of Sun et al. and the studies of Marom et al. and Sturla et al. explained the merit of using FSI simulation compared to FE "dry" models[89][84][87]. For example, the momentum of blood flow produces a closing impulse that is not modeled in "dry" FE [76]. The prosthesis leaflets may be overly opened when simulating systole. The blood flow model grants damping that smooth the movement of the leaflets.

\section{Deployment steps\& Balloon expansion}

An efficient and reliable simulation requires modeling boundary conditions as closely as necessary to the real conditions of the procedure. Deployment is usually composed of two steps. The crimping of the stent consists in compressing the stent so that its size fits in the arteries. Then, a balloon inside the prosthesis expands it (in the case of SAPIEN). Little to no data is given about the method to center the balloon during deployment. It seems that a number of studies arbitrarily align the balloon in the center of the valve. In practice, the balloon centers 
itself during expansion. However, the boundary conditions at the edge of geometry are often in total constraint, so they likely prevent the balloon from 'auto-centering'. As previously stated, current models focus on the results of the deployment, such as stresses and deformations. It does not matter that the prosthesis does not take a realistic path during the deployment, as long as the prosthesis is correctly positioned in the end of simulation. However, a more realistic description of the boundary conditions of the balloon could allow realistic simulation of the migrations which may occur during deployment.

The models of the balloon expansion in simulation studieswere relatively simple for a long time. However, recent studies suggest that the expansion model is important. Capelli et al. [51] and Auricchio et al. [57]used a uniform pressure expansion to deploy the balloon. Morganti et al.[59] and Wang et al. [52] initially used a plain cylinder. Its nodes were constrained in displacement in order to simulate the deployment. In the case of a CoreValve deployment, Russ et al. [54]suggested a rare method of deployment. It did not use a balloon, and displacements were directly applied to the stent. In order to crimp the prosthesis, the extremities of the stent frame were stretched. Then, the deployment consisted in squeezing the extremities. Eventually, this idea was not exploited in other studies.

While most balloon inflations were straightforward in previous studies, Wang et al. [58]challenged the use of uniform pressure expansion. Instead, the balloon was inflated based on a volume variable method [121]. This method was originally applied to angioplasty, and focused on the transitory radial force during the expansion. It showed that the force is influenced more by the diameter of the balloon than by the filling pressure. In practice, TAVI operators do not control the pressure, but rather the injected volume inside the balloon. Furthermore, the operators can choose to use an oversized balloon and prosthesis, without completely filling the balloon, in order to facilitate deployment. That is something that may not be simulated realistically with uniform pressure.

\section{Summary}

Boundary conditions represent a very large question in numerical simulation. There is no definite answer as to what should be simplified or neglected and what should be accurately modeled. The method of simulation itself limits the choice, as FE analysis does not allow realistic models of blood flow. While it may not be a problem for quick balloon-expandable deployment, it may be so for self-expanding prostheses. Indeed, those prostheses "swim" along their guidewire and are constantly moving with the blood flow during the deployment.

Many physiological conditions cannot be entirely grasped. Heart Burst Stimulation is not modeled at all, yet the geometrical model may greatly change as it contracts the muscle fibers. However, modeling the myocardium activation in the deployment for in-vivo tissues obviously seem a cumbersome task compared to how it may benefit to the accuracy of the simulation. Moreover, accurate descriptions of deployment tools are missing in the current studies, such as the guidewire of the TAV. Balloons are always spatially fixed, while in practice they are free to move along their guidewire. Hence, current studies completely neglect the aspect of deployment where the prosthesis is liable to migrate. However small, the prosthesis migration has different degrees across the different type of prosthesis. Medical teams are interested in it to plan their prosthesis delivery[28].

\section{Data analysis}

\subsection{Simulation outputs}

The stresses induced on the aortic wall are relevant to assess the risk of aortic injury, and were often reported[51][52][57][59][60]. Stresses on the stent are also relevant as they may be related to the prosthesis durability. Also, contact force between the stent and the aortic wall is relevant to assess the risk of migration of the prosthesis. However, patient-specific simulation did not systematically report contact force.

An important result of simulation is the final shape of the geometries. Wang et al. [52][58]and Morganti et al. [59]reported the gaps between the deployed stent and the aortic wall. Indeed, these gaps are crucial to predicting paravalvular leaks. Morganti et al.[59]showed that those leaks could be estimated for the case of two patients, by observing their retrograde blood flow. 
When calcified native leaflets are modeled, the observation of their final shape can inform clinicians on the occurrence of coronary occlusion. Indeed, coronary occlusion sometimes happens from the displacement of bulky calcified leaflets over the coronary ostium [6].

The final shape of the stent also greatly impacts the behavior of the prosthesis leaflets [43]. The behavior of the leaflets determines the stress distribution and the transvalvular leaks. Transvalvular leaks are believed to be related to the coaptation area between the leaflets during diastole. Auricchio et al. [57]and Gunning et al. [60] simulated the valve closure at diastole by prescribing pressure at each side of the leaflets.

Clinicians usually evaluate the severity of stenosis through pressure gradient, which is the difference of pressure at both sides of the valve. Sirois et al.[8] and Capelli et al. [51]suggested measuring the geometric orifice area of the aortic valve before and after deployment of the prosthesis. Sadly, the conditions of measurement were not specified. Subsequent patient-specific TAVI simulations dropped this aspect. While geometric area has a strong correlation with energy loss at systole, a more precise fluid mechanics simulation of the implanted prosthesis could be relevant during the whole cardiac cycle. Sirois et al.[8]computed turbulent kinetic energy from CFD simulation.

One of the interests of simulating deployment without focusing on the starting deployment position is the search for the optimal position of the landing site. Several studies tested several positions of implantation and compared their performances. Capelli et al.[51] showed that geometric orifice area could vary according to the implantation depth. Auricchio et al. [57]compared two extreme positions of prosthesis in terms of aortic wall stress, TAV leaflets stress, and coaptation area. There is no CFD study on this aspect yet. However, Groves et al. showed through experimental setup that the position of TAV had an impact on the flow[62]. The position of the valve changed the aortic wall stress and residence time of blood particles in the aortic root. It is speculated that the residence time of blood within the aortic root also influenced the coronary perfusion. Those studies on the optimal position of prosthesis pave the way towards the use of patient-specific simulation for clinical planning.

Dwyer et al. [50]expressed concern over the orientation of the TAV prosthesis. Indeed, it has a free axis of rotation, as it may rotate around its guidewire, c.f. Fig.14. Gunning et al.[60]studied the impact of this orientation on the prosthesis.

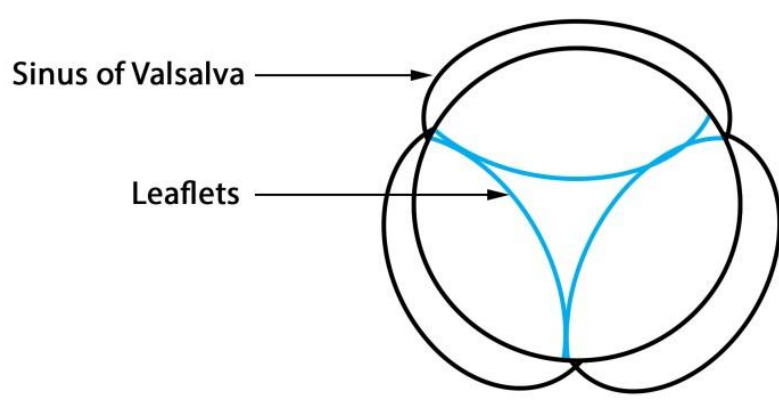

Normal orientation

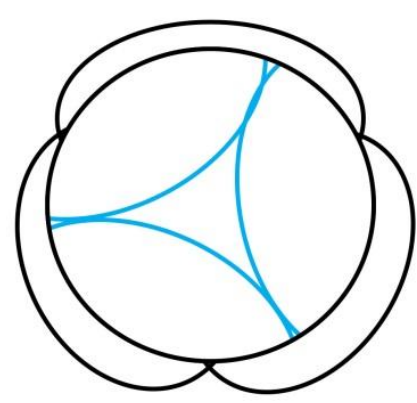

Randomly oriented TAV

Fig.14 Upper view of aortic valve, orientation of prosthesis compared to sinus configuration

\section{2. Perspectives}

Currently, the presented parameters already offer interesting insight to clinicians. There is no doubt that they can still be further developed. Some examples are given in this section.

The native leaflets are tied and aligned at the base of a sinus, which plays a role in the normal function of the valve (c.f. Fig.14). The sinus shape evens out the stress, and helps the valve closure during diastole [69][77][79]. The impact of orientation on the motion of leaflets has not been studied yet.

Atrioventricular Block is supposed to be related to the stress distribution on the aortic wall. Larger models to obtain a precise map of stresses would help predicting this complication. 
Current models of TAV post-operative action are still lacking as it was partially treated very recently by very few studies. As mentioned in the boundary condition section, FE "dry" simulation neglects the aortic wall deformation and focuses on a specific phase of the cardiac cycle, while differences in deformation between the wall and the stent may result in unwanted friction.

\section{Conclusion}

TAVI simulations are still in an active period as new studies offer increasingly accurate models. Models significantly differ from each other, from the choice in geometry, mechanical properties and boundary conditions. Current studies lack statistical data to firmly justify those choices. Therefore they may not be reliable enough to offer precise quantitative estimations, though they can help medical teams [58]. Precaution is still needed when applying current models to clinical use.

Current patient-specific simulations put an emphasis on the end of deployment step and prosthesis action. However, they do not tackle the placement shift and migration that occur during deployment. Yet, these are major issues in TAVI as misplacement can have catastrophic outcomes, e.g. coronary occlusion, supra-skirtal leaks, and ventricle migration. Choosing the best starting positions for the deployment is a big concern for medical teams, especially in cases in which the deployment mechanism does not allow for recapture of the prosthesis or is difficult to predict. Thus, numerous challenges are awaiting patient-specific simulations.

\section{Disclosure}

P. Vy and M. Rochette are full-time employees of ANSYS France. H. Le Breton hadreceived speaker honorarium from Edwards Lifesciences.

\section{References}

[1] D. H. Adams, J. J. Popma, M. J. Reardon, S. J. Yakubov, J. S. Coselli, G. M. Deeb, T. G. Gleason, M. Buchbinder, J. Hermiller, N. S. Kleiman, S. Chetcuti, J. Heiser, W. Merhi, G. Zorn, P. Tadros, N. Robinson, G. Petrossian, G. C. Hughes, J. K. Harrison, J. Conte, B. Maini, M. Mumtaz, S. Chenoweth, and J. K. Oh, "Transcatheter Aortic-Valve Replacement with a Self-Expanding Prosthesis.," N. Engl. J. Med., vol. 370, pp. 1790-8, 2014.

[2] C. Smith and M. Leon, "Transcatheter versus Surgical Aortic-Valve Replacement in High-Risk Patients,” N. Engl. J. Med., vol. 364, no. 23, pp. 2187-98, 2011.

[3] M. B. Leon, C. R. Smith, M. Mack, D. C. Miller, J. W. Moses, L. G. Svensson, E. M. Tuzcu, J. G. Webb, G. P. Fontana, R. R. Makkar, D. L. Brown, P. C. Block, R. A. Guyton, A. D. Pichard, J. E. Bavaria, H. C. Herrmann, P. S. Douglas, J. L. Petersen, J. J. Akin, W. N. Anderson, D. Wang, and S. Pocock, "Transcatheter aortic-valve implantation for aortic stenosis in patients who cannot undergo surgery.," N. Engl. J. Med., vol. 363, no. 17, pp. 1597-1607, 2010.

[4] A. Cribier, H. Eltchaninoff, A. Bash, N. Borenstein, C. Tron, F. Bauer, G. Derumeaux, F. Anselme, F. Laborde, and M. B. Leon, "Percutaneous transcatheter implantation of an aortic valve prosthesis for calcific aortic stenosis: First human case description," Circulation, vol. 106, no. 24, pp. 3006-3008, 2002.

[5] A. N. Azadani, N. Jaussaud, P. B. Matthews, L. Ge, T. S. Guy, T. a M. Chuter, and E. E. Tseng, "Energy loss due to paravalvular leak with transcatheter aortic valve implantation.," Ann. Thorac. Surg., vol. 88, no. 6, pp. 1857-1863, 2009.

[6] J. B. Masson, J. Kovac, G. Schuler, J. Ye, A. Cheung, S. Kapadia, M. E. Tuzcu, S. Kodali, M. B. Leon, and J. G. Webb, "Transcatheter Aortic Valve Implantation. Review of the Nature, Management, and Avoidance of Procedural Complications," JACC Cardiovasc. Interv., vol. 2, no. 9, pp. 811-820, 2009. 
[7] J. Shannon, M. Mussardo, A. Latib, K. Takagi, A. Chieffo, M. Montorfano, and A. Colombo, "Recognition and management of complications during transcatheter aortic valve implantation.," Expert Rev. Cardiovasc. Ther., vol. 9, pp. 913-926, 2011.

[8] E. Sirois, Q. Wang, and W. Sun, "Fluid Simulation of a Transcatheter Aortic Valve Deployment into a Patient-Specific Aortic Root,” Cardiovasc. Eng. Technol., vol. 2, no. 3, pp. 186-195, 2011.

[9] A. Vahanian, O. Alfieri, F. Andreotti, M. J. Antunes, G. Barón-Esquivias, H. Baumgartner, M. A. Borger, T. P. Carrel, M. De Bonis, A. Evangelista, V. Falk, B. Iung, P. Lancellotti, L. Pierard, S. Price, H. J. Schäfers, G. Schuler, J. Stepinska, K. Swedberg, J. Takkenberg, U. O. Von Oppell, S. Windecker, J. L. Zamorano, M. Zembala, J. J. Bax, C. Ceconi, V. Dean, C. Deaton, R. Fagard, C. Funck-Brentano, D. Hasdai, A. Hoes, P. Kirchhof, J. Knuuti, P. Kolh, T. McDonagh, C. Moulin, B. a. Popescu, Ž. Reiner, U. Sechtem, P. A. Sirnes, M. Tendera, A. Torbicki, L. Von Segesser, L. P. Badano, M. Bunc, M. J. Claeys, N. Drinkovic, G. Filippatos, G. Habib, a. Pieter Kappetein, R. Kassab, G. Y. H. Lip, N. Moat, G. Nickenig, C. M. Otto, J. Pepper, N. Piazza, P. G. Pieper, R. Rosenhek, N. Shuka, E. Schwammenthal, J. Schwitter, P. T. Mas, P. T. Trindade, and T. Walther, "Guidelines on the management of valvular heart disease (version 2012)," Eur. Heart J., vol. 33, no. 19, pp. 2451-2496, 2012.

[10] B. Iung, G. Baron, E. G. Butchart, F. Delahaye, C. Gohlke-Bärwolf, O. W. Levang, P. Tornos, J. L. Vanoverschelde, F. Vermeer, E. Boersma, P. Ravaud, and A. Vahanian, “A prospective survey of patients with valvular heart disease in Europe: The Euro Heart Survey on valvular heart disease," Eur. Heart J., vol. 24, no. 13, pp. 1231-1243, 2003.

[11] G. W. Eveborn, H. Schirmer, G. Heggelund, P. Lunde, and K. Rasmussen, "The evolving epidemiology of valvular aortic stenosis. The Tromso Study," Heart. 2012.

[12] C. Clark, "Energy losses in flow through stenosed valves.," J. Biomech., vol. 12, no. December 1978, pp. 737-746, 1979.

[13] D. Garcia and L. Kadem, “Orifice Area , Effective Orifice Area , or Gorlin Area ?,” 2006.

[14] P. Dyverfeldt, M. D. Hope, E. E. Tseng, and D. Saloner, "Magnetic resonance measurement of turbulent kinetic energy for the estimation of irreversible pressure loss in aortic stenosis," JACC Cardiovasc. Imaging, vol. 6, no. 1, pp. 64-71, 2013.

[15] C. MD, G. EW, B. BH, C. CJ, Q. JA, and B. R. Jr., "Rate of progression of severity of valvular aortic stenosis in the adult.," Am. Heart J., vol. 98, no. 6, pp. 689-700, 1979.

[16] J. Turina, O. Hess, F. Sepulcri, and H. P. Krayenbuehl, "Spontaneous course of aortic valve disease.," Eur. Heart J., vol. 8, no. 5, pp. 471-483, 1987.

[17] C. M. Otto, “Timing of aortic valve surgery CatherineMOtto," Circulation, pp. 211-218, 2000.

[18] P. Kleine, M. J. Hasenkam, H. Nygaard, M. Perthel, D. Wesemeyer, and J. Laas, “Tilting disc versus bileaflet aortic valve substitutes: intraoperative and postoperative hemodynamic performance in humans.," 2000.

[19] V. Goyal, S. Devgarha, S. Kalla, and C. P. Srivastava, "Comparative evaluation of hemodynamic performance in early post-operative period of tilting disc vs. bileaflet mechanical valve at mitral position — A prospective study," Indian J. Thorac. Cardiovasc. Surg., vol. 25, no. 2, pp. 52-55, Jun. 2009.

[20] W. S. EDWARDS and L. SMITH, “Aortic valve replacement with a subcoronary ball valve.," Surg. Forum, vol. 9, pp. 309-313, 1958.

[21] W. S. Edwards, “Aortic valve replacement with a subcoronary ball valve--early experiments.," Med. Instrum., vol. 11, no. 2, pp. 77-79, 1977. 
[22] M. Neyt, H. Van Brabandt, S. Van De Sande, and S. Devriese, "Transcatheter Aortic Valve Implantation (TAVI): a Health Technology Assessment Update," 2011.

[23] M. A. Clark, F. G. Duhay, A. K. Thompson, M. J. Keyes, L. G. Svensson, R. O. Bonow, B. T. Stockwell, and D. J. Cohen, "Clinical and economic outcomes after surgical aortic valve replacement in Medicare patients,” Risk Manag. Healthc. Policy, vol. 5, pp. 117-126, 2012.

[24] B. A. Carabello and W. J. Paulus, “Aortic stenosis,” The Lancet, vol. 373, no. 9667. pp. 956-966, 2009.

[25] B. Iung and A. Vahanian, "Epidemiology of valvular heart disease in the adult.," Nat. Rev. Cardiol., vol. 8, no. 3, pp. 162-172, 2011.

[26] R. L. J. Osnabrugge, D. Mylotte, S. J. Head, N. M. Van Mieghem, V. T. Nkomo, C. M. Lereun, A. J. J. C. Bogers, N. Piazza, and a. P. Kappetein, "Aortic stenosis in the elderly: Disease prevalence and number of candidates for transcatheter aortic valve replacement: A meta-analysis and modeling study," J. Am. Coll. Cardiol., vol. 62, no. 11, pp. 1002-1012, 2013.

[27] A. Ielasi, A. Latib, and M. Tespili, "Current and new-generation transcatheter aortic valve devices: an update on emerging technologies.," Expert Rev. Cardiovasc. Ther., vol. 11, pp. 1393-405, 2013.

[28] D. Dvir, I. Lavi, H. Eltchaninoff, D. Himbert, Y. Almagor, F. Descoutures, A. Vahanian, C. Tron, A. Cribier, and R. Kornowski, "Multicenter evaluation of Edwards SAPIEN positioning during transcatheter aortic valve implantation with correlates for device movement during final deployment.," JACC. Cardiovasc. Interv., vol. 5, no. 5, pp. 563-70, May 2012.

[29] C. Cao, "Migration of transcatheter valve into the left ventricle," 2012.

[30] G. Schymik, H. Schröfel, M. Heimeshoff, A. Luik, M. Thoenes, and L. Mandinov, "How to Adapt the Implantation Technique for the New SAPIEN 3 Transcatheter Heart Valve Design," J. Interv. Cardiol., vol. 28 , no. 1, pp. 82-89, 2015.

[31] L. Lehmkuhl, B. Foldyna, K. Von Aspern, C. Lücke, M. Grothoff, S. Nitzsche, J. Kempfert, M. Haensig, A. Rastan, T. Walther, F.-W. Mohr, and M. Gutberlet, "Inter-individual variance and cardiac cycle dependency of aortic root dimensions and shape as assessed by ECG-gated multi-slice computed tomography in patients with severe aortic stenosis prior to transcatheter aortic valve implantation: is it crucial for," Int. J. Cardiovasc. Imaging, vol. 29, no. 3, pp. 693-703, Mar. 2013.

[32] H. B. Ribeiro, L. Nombela-Franco, M. Urena, M. Mok, S. Pasian, D. Doyle, R. Delarochellière, M. Côté, L. Laflamme, H. Delarochellière, R. Allende, E. Dumont, and J. Rodés-Cabau, "Coronary obstruction following transcatheter aortic valve implantation: A systematic review," JACC: Cardiovascular Interventions, vol. 6, no. 5. pp. 452-461, 2013.

[33] R. G. Seipelt, G. Hanekop, F. A. Schoendube, and W. Schillinger, "Heart team approach for transcatheter aortic valve implantation procedures complicated by coronary artery occlusion.," Interact. Cardiovasc. Thorac. Surg., vol. 14, no. 4, pp. 431-3, 2012.

[34] G. C. M. Siontis, P. Jüni, T. Pilgrim, S. Stortecky, L. Büllesfeld, B. Meier, P. Wenaweser, and S. Windecker, "Predictors of Permanent Pacemaker Implantation in Patients With Severe Aortic Stenosis Undergoing TAVR,” J. Am. Coll. Cardiol., vol. 64, no. 2, pp. 129-140, 2014.

[35] A. N. Azadani, N. Jaussaud, P. B. Matthews, L. Ge, T. a M. Chuter, and E. E. Tseng, "Transcatheter aortic valves inadequately relieve stenosis in small degenerated bioprostheses.," Interact. Cardiovasc. Thorac. Surg., vol. 11, pp. 70-77, 2010.

[36] M. A. Clavel, J. G. Webb, P. Pibarot, L. Altwegg, E. Dumont, C. Thompson, R. De Larochellière, D. Doyle, J. B. Masson, S. Bergeron, O. F. Bertrand, and J. Rodés-Cabau, "Comparison of the 
Hemodynamic Performance of Percutaneous and Surgical Bioprostheses for the Treatment of Severe Aortic Stenosis," J. Am. Coll. Cardiol., vol. 53, no. 20, pp. 1883-1891, 2009.

[37] S. H. Ewe, M. Muratori, V. Delgado, M. Pepi, G. Tamborini, L. Fusini, R. J. M. Klautz, P. Gripari, J. J. Bax, M. Fusari, M. J. Schalij, and N. A. Marsan, "Hemodynamic and clinical impact of prosthesispatient mismatch after transcatheter aortic valve implantation," J. Am. Coll. Cardiol., vol. 58, no. 18, pp. 1910$1918,2011$.

[38] M. Pasic, A. Unbehaun, S. Buz, T. Drews, and R. Hetzer, "Annular Rupture During Transcatheter Aortic Valve Replacement,” JACC Cardiovasc. Interv., vol. 8, no. 1, pp. 1-9, 2015.

[39] K. Hayashida, E. Bouvier, T. Lefèvre, T. Hovasse, M.-C. Morice, B. Chevalier, M. Romano, P. Garot, A. Farge, P. Donzeau-Gouge, and B. Cormier, "Potential mechanism of annulus rupture during transcatheter aortic valve implantation.," Catheter. Cardiovasc. Interv., vol. 82, no. 5, pp. E742-6, Nov. 2013.

[40] P. Généreux, S. J. Head, R. Hahn, B. Daneault, S. Kodali, M. R. Williams, N. M. Van Mieghem, M. C. Alu, P. W. Serruys, A. P. Kappetein, and M. B. Leon, "Paravalvular leak after transcatheter aortic valve replacement: The new achilles' heel? A comprehensive review of the literature," Journal of the American College of Cardiology, vol. 61, no. 11. pp. 1125-1136, 2013.

[41] R. Zegdi, V. Ciobotaru, M. Noghin, G. Sleilaty, A. Lafont, C. Latrémouille, A. Deloche, and J.-N. Fabiani, "Is it reasonable to treat all calcified stenotic aortic valves with a valved stent? Results from a human anatomic study in adults.," J. Am. Coll. Cardiol., vol. 51, no. 5, pp. 579-84, Feb. 2008.

[42] B. E. Stähli, W. Maier, R. Corti, T. F. Lüscher, R. Jenni, and F. C. Tanner, "Aortic regurgitation after transcatheter aortic valve implantation: mechanisms and implications.," Cardiovasc. Diagn. Ther., vol. 3 , no. 1, pp. 15-22, 2013.

[43] W. Sun, K. Li, and E. Sirois, "Simulated elliptical bioprosthetic valve deformation: implications for asymmetric transcatheter valve deployment.," J. Biomech., vol. 43, no. 16, pp. 3085-90, Dec. 2010.

[44] P. Kahlert, F. Al-Rashid, P. Döttger, K. Mori, B. Plicht, D. Wendt, L. Bergmann, E. Kottenberg, M. Schlamann, P. Mummel, D. Holle, M. Thielmann, H. G. Jakob, T. Konorza, G. Heusch, R. Erbel, and H. Eggebrecht, "Cerebral embolization during transcatheter aortic valve implantation: A transcranial doppler study," Circulation, vol. 126, no. 10, pp. 1245-1255, 2012.

[45] C. K. Naber, A. Ghanem, A. A. Abizaid, A. Wolf, J. M. Sinning, N. Werner, G. Nickenig, T. Schmitz, and E. Grube, "First-in-man use of a novel embolic protection device for patients undergoing transcatheter aortic valve implantation," EuroIntervention, vol. 8, no. 1, pp. 43-50, 2012.

[46] J. G. Webb and D. A. Wood, "Current status of transcatheter aortic valve replacement," J. Am. Coll. Cardiol., vol. 60, no. 6, pp. 483-492, 2012.

[47] E. E. Tseng, A. Wisneski, A. N. Azadani, and L. Ge, "Engineering perspective on transcatheter aortic valve implantation,” Interv. Cardiol., vol. 5, pp. 53-70, 2013.

[48] J.G. Webb, "Percutaneous aortic valve replacement in selected high risk patients with aortic stenosis," 2007.

[49] I. B., L. C., H. D., E. H., C. K., D.-G. P., F. J., L. P., L. a., L. M., P. a., T. E., L. M., V. a., and G. M., "Predictive factors of early mortality after transcatheter aortic valve implantation: Individual risk assessment using a simple score," Heart, vol. 100, no. 13, pp. 1016-1023, 2014.

[50] H. a Dwyer, P. B. Matthews, A. Azadani, N. Jaussaud, L. Ge, T. S. Guy, and E. E. Tseng, "Computational fluid dynamics simulation of transcatheter aortic valve degeneration.," Interact. Cardiovasc. Thorac. Surg., vol. 9, pp. 301-308, 2009. 
[51] C. Capelli, G. M. Bosi, E. Cerri, J. Nordmeyer, T. Odenwald, P. Bonhoeffer, F. Migliavacca, a M. Taylor, and S. Schievano, "Patient-specific simulations of transcatheter aortic valve stent implantation.," Med. Biol. Eng. Comput., vol. 50, no. 2, pp. 183-92, Feb. 2012.

[52] Q. Wang, E. Sirois, and W. Sun, "Patient-specific modeling of biomechanical interaction in transcatheter aortic valve deployment.," J. Biomech., vol. 45, no. 11, pp. 1965-71, Jul. 2012.

[53] R. Hopf, M. Gessat, V. Falk, and E. Mazza, "Reconstruction of Stent Induced Loading Forces on the Aortic Valve Complex," pp. 104-111, 2012.

[54] C. Russ, R. Hopf, S. Hirsch, S. Sundermann, V. Falk, G. Szekely, and M. Gessat, "Simulation of transcatheter aortic valve implantation under consideration of leaflet calcification.," Conf. Proc. IEEE Eng. Med. Biol. Soc., vol. 2013, pp. 711-4, Jan. 2013.

[55] S. Tzamtzis, J. Viquerat, J. Yap, M. J. Mullen, and G. Burriesci, "Numerical analysis of the radial force produced by the Medtronic-CoreValve and Edwards-SAPIEN after transcatheter aortic valve implantation (TAVI).," Med. Eng. Phys., vol. 35, no. 1, pp. 125-30, Jan. 2013.

[56] I. Kemp, K. Dellimore, R. Rodriguez, C. Scheffer, D. Blaine, H. Weich, and a. Doubell, "Experimental validation of the fluid-structure interaction simulation of a bioprosthetic aortic heart valve," Australas. Phys. Eng. Sci. Med., vol. 36, no. 3, pp. 363-373, 2013.

[57] F. Auricchio, M. Conti, S. Morganti, and a Reali, "Simulation of transcatheter aortic valve implantation: a patient-specific finite element approach.," Comput. Methods Biomech. Biomed. Engin., vol. 17, no. 12, pp. 1347-57, Jan. 2014.

[58] Q. Wang, S. Kodali, C. Primiano, and W. Sun, "Simulations of transcatheter aortic valve implantation: implications for aortic root rupture.," Biomech. Model. Mechanobiol., Apr. 2014.

[59] S. Morganti, M. Conti, M. Aiello, a Valentini, a Mazzola, a Reali, and F. Auricchio, "Simulation of transcatheter aortic valve implantation through patient-specific finite element analysis: Two clinical cases.," J. Biomech., no. 2012, Jun. 2014.

[60] P. S. Gunning, T. J. Vaughan, and L. M. McNamara, "Simulation of Self Expanding Transcatheter Aortic Valve in a Realistic Aortic Root: Implications of Deployment Geometry on Leaflet Deformation," Ann. Biomed. Eng., vol. 42, no. 9, pp. 1989-2001, 2014.

[61] M. Gessat, R. Hopf, T. Pollok, C. Russ, T. Frauenfelder, S. H. Sundermann, S. Hirsch, E. Mazza, G. Szekely, and V. Falk, "Image-based mechanical analysis of stent deformation: Concept and exemplary implementation for aortic valve stents," IEEE Trans. Biomed. Eng., vol. 61, no. c, pp. 4-15, 2014.

[62] E. M. Groves, A. Falahatpisheh, J. L. Su, and A. Kheradvar, "The Effects of Positioning of Transcatheter Aortic Valves on Fluid Dynamics of the Aortic Root,” ASAIO J., vol. 60, pp. 545-552, 2014.

[63] A. Kheradvar, E. M. Groves, C. J. Goergen, S. H. Alavi, R. Tranquillo, C. a. Simmons, L. P. Dasi, K. J. Grande-Allen, M. R. K. Mofrad, A. Falahatpisheh, B. Griffith, F. Baaijens, S. H. Little, and S. Canic, "Emerging Trends in Heart Valve Engineering: Part II. Novel and Standard Technologies for Aortic Valve Replacement," Ann. Biomed. Eng., 2014.

[64] F. Sotiropoulos, "Computational Fluid Dynamics for Medical Device Design and Evaluation: Are We There Yet?," Cardiovascular Engineering and Technology, vol. 3, no. 2, pp. 137-138, 2012.

[65] S. F. C. Stewart, E. G. Paterson, G. W. Burgreen, P. Hariharan, M. Giarra, V. Reddy, S. W. Day, K. B. Manning, S. Deutsch, M. R. Berman, M. R. Myers, and R. a. Malinauskas, “Assessment of CFD Performance in Simulations of an Idealized Medical Device: Results of FDA's First Computational Interlaboratory Study," Cardiovasc. Eng. Technol., vol. 3, no. 2, pp. 139-160, 2012. 
[66] E. Votta, T. B. Le, M. Stevanella, L. Fusini, E. G. Caiani, A. Redaelli, and F. Sotiropoulos, "Toward patient-specific simulations of cardiac valves: State-of-the-art and future directions," J. Biomech., vol. 46, no. 2, pp. 217-228, 2013.

[67] S. Krucinski, I. Vesely, M. a. Dokainish, and G. Campbell, "Numerical simulation of leaflet flexure in bioprosthetic valves mounted on rigid and expansile stents," J. Biomech., vol. 26, no. 8, pp. 929-943, 1993.

[68] K. J. Grande, R. P. Cochran, P. G. Reinhall, and K. S. Kunzelman, "Stress variations in the human aortic root and valve: the role of anatomic asymmetry.," Ann. Biomed. Eng., vol. 26, no. 4, pp. 534-545, 1998.

[69] K. J. Grande-Allen, R. P. Cochran, P. G. Reinhall, and K. S. Kunzelman, "Re-creation of sinuses is important for sparing the aortic valve: a finite element study.," J. Thorac. Cardiovasc. Surg., vol. 119, no. 4 Pt 1, pp. 753-763, 2000.

[70] R. Gnyaneshwar, R. K. Kumar, and K. R. Balakrishnan, "Dynamic analysis of the aortic valve using a finite element model.," Ann. Thorac. Surg., vol. 73, no. 01, pp. 1122-9, 2002.

[71] I. C. Howard, E. a Patterson, and a Yoxall, "On the opening mechanism of the aortic valve: some observations from simulations.," J. Med. Eng. Technol., vol. 27, no. 6, pp. 259-266, 2003.

[72] M. a. Nicosia, R. P. Cochran, and K. S. Kunzelman, "Coupled fluid-structure finite element modeling of the aortic valve and root," Proc. Second Jt. 24th Annu. Conf. Annu. Fall Meet. Biomed. Eng. Soc. [Engineering Med. Biol., vol. 2, no. 5, pp. 1278-1279, 2002.

[73] C. Carmody, G. Burriesci, I. Howard, and E. Patterson, "The use of LS-DYNA fluid-structure interaction to simulate fluid-driven deformation in the aortic valve.," no. 0, pp. 11-20, 2003.

[74] J. De Hart, F. P. T. Baaijens, G. W. M. Peters, and P. J. G. Schreurs, "A computational fluid-structure interaction analysis of a fiber-reinforced stentless aortic valve,” J. Biomech., vol. 36, no. 5, pp. 699-712, 2003.

[75] G. Arcidiacono, a. Corvi, and T. Severi, "Functional analysis of bioprosthetic heart valves," J. Biomech., vol. 38, no. 7, pp. 1483-1490, 2005.

[76] D. R. Hose, A. J. Narracott, J. M. T. Penrose, D. Baguley, I. P. Jones, and P. V. Lawford, "Fundamental mechanics of aortic heart valve closure," J. Biomech., vol. 39, no. 5, pp. 958-967, 2006.

[77] A. Ranga, O. Bouchot, R. Mongrain, P. Ugolini, and R. Cartier, "Computational simulations of the aortic valve validated by imaging data: evaluation of valve-sparing techniques.," Interact. Cardiovasc. Thorac. Surg., vol. 5, no. 4, pp. 373-378, 2006.

[78] E. J. Weinberg and M. R. Kaazempur Mofrad, "Transient, three-dimensional, multiscale simulations of the human aortic valve.," Cardiovasc. Eng., vol. 7, no. 4, pp. 140-155, 2007.

[79] S. Katayama, N. Umetani, S. Sugiura, and T. Hisada, "The sinus of Valsalva relieves abnormal stress on aortic valve leaflets by facilitating smooth closure," J. Thorac. Cardiovasc. Surg., vol. 136, no. 6, pp. 1528-1535.e1, 2008.

[80] F. Viscardi, C. Vergara, L. Antiga, S. Merelli, A. Veneziani, G. Puppini, G. Faggian, A. Mazzucco, and G. B. Luciani, "Comparative Finite Element Model Analysis of Ascending Aortic Flow in Bicuspid and Tricuspid Aortic Valve,” Artif. Organs, vol. 34, no. 12, pp. 1114-1120, 2010.

[81] C. a Conti, E. Votta, A. Della Corte, L. Del Viscovo, C. Bancone, M. Cotrufo, and A. Redaelli, "Dynamic finite element analysis of the aortic root from MRI-derived parameters.," Med. Eng. Phys., vol. 32, no. 2, pp. 212-221, 2010. 
[82] M. R. Labrosse, K. Lobo, and C. J. Beller, "Structural analysis of the natural aortic valve in dynamics: From unpressurized to physiologically loaded," J. Biomech., vol. 43, no. 10, pp. 1916-1922, 2010.

[83] T. M. Koch, B. D. Reddy, P. Zilla, and T. Franz, "Aortic valve leaflet mechanical properties facilitate diastolic valve function.," Comput. Methods Biomech. Biomed. Engin., vol. 13, no. 2, pp. 225-234, 2010 .

[84] G. Marom, R. Haj-Ali, E. Raanani, H. J. Schäfers, and M. Rosenfeld, "A fluid-structure interaction model of the aortic valve with coaptation and compliant aortic root," Med. Biol. Eng. Comput., vol. 50, no. 2, pp. 173-182, 2012.

[85] I. Borazjani, "Fluid-structure interaction, immersed boundary-finite element method simulations of bioprosthetic heart valves," Comput. Methods Appl. Mech. Eng., vol. 257, pp. 103-116, 2013.

[86] G. Marom, M. Peleg, R. Halevi, M. Rosenfeld, E. Raanani, A. Hamdan, and R. Haj-Ali, "Fluid-structure interaction model of aortic valve with porcine-specific collagen fiber alignment in the cusps.," $J$. Biomech. Eng., vol. 135, no. 10, pp. 101001-6, 2013.

[87] F. Sturla, E. Votta, M. Stevanella, C. a. Conti, and A. Redaelli, "Impact of modeling fluid-structure interaction in the computational analysis of aortic root biomechanics," Med. Eng. Phys., vol. 35, no. 12, pp. 1721-1730, 2013.

[88] M. Y. S. Kuan and D. M. Espino, "Systolic fluid-structure interaction model of the congenitally bicuspid aortic valve: assessment of modelling requirements.," Comput. Methods Biomech. Biomed. Engin., no. August, pp. 37-41, 2014.

[89] W. Sun, C. Martin, and T. Pham, "Computational modeling of cardiac valve function and intervention.," Annu. Rev. Biomed. Eng., vol. 16, pp. 53-76, 2014.

[90] G. Marom, "Numerical Methods for Fluid - Structure Interaction Models of Aortic Valves,” 2014.

[91] M. Swanson and R. E. Clark, "Dimensions and geometric relationships of the human aortic valve as a function of pressure.," Circ. Res., vol. 35, no. 6, pp. 871-882, 1974.

[92] C. J. Chuong and Y. C. Fung, “Three-dimensional stress distribution in arteries.," J. Biomech. Eng., vol. 105, no. 3, pp. 268-274, 1983.

[93] W. Huang and R. T. Yen, "Zero-stress states of human pulmonary arteries and veins.," J. Appl. Physiol., vol. 85 , no. 3 , pp. 867-873, 1998.

[94] J. Zhao, J. Day, Z. F. Yuan, and H. Gregersen, "Regional arterial stress-strain distributions referenced to the zero-stress state in the rat.," Am. J. Physiol. Heart Circ. Physiol., vol. 282, no. 2, pp. H622-H629, 2002 .

[95] X. Huang, C. Yang, C. Yuan, F. Liu, G. Canton, J. Zheng, P. K. Woodard, G. a Sicard, and D. Tang, "Patient-specific artery shrinkage and 3D zero-stress state in multi-component 3D FSI models for carotid atherosclerotic plaques based on in vivo MRI data.," Mol. Cell. Biomech., vol. 6, no. 2, pp. 121-134, 2009.

[96] L. Speelman, E. M. H. Bosboom, G. W. H. Schurink, J. Buth, M. Breeuwer, M. J. Jacobs, and F. N. van de Vosse, "Initial stress and nonlinear material behavior in patient-specific AAA wall stress analysis.," $J$. Biomech., vol. 42, no. 11, pp. 1713-9, Aug. 2009.

[97] S. Grbic, T. Mansi, R. Ionasec, I. Voigt, H. Houle, M. John, M. Schoebinger, N. Navab, and D. Comaniciu, "Image-based computational models for TAVI planning: From CT images to implant deployment," in Lecture Notes in Computer Science (including subseries Lecture Notes in Artificial Intelligence and Lecture Notes in Bioinformatics), 2013, vol. 8150 LNCS, no. PART 2, pp. 395-402. 
[98] R. Haj-Ali, G. Marom, S. Ben Zekry, M. Rosenfeld, and E. Raanani, "A general three-dimensional parametric geometry of the native aortic valve and root for biomechanical modeling," J. Biomech., vol. 45, no. 14, pp. 2392-2397, 2012.

[99] J. S. Rankin, M. C. Bone, P. M. Fries, D. Aicher, H. J. Schäfers, and P. S. Crooke, “A refined hemispheric model of normal human aortic valve and root geometry," J. Thorac. Cardiovasc. Surg., vol. 146, no. 1, 2013.

[100] Y. Zheng, M. John, R. Liao, A. Nöttling, J. Boese, J. Kempfert, T. Walther, G. Brockmann, and D. Comaniciu, "Automatic aorta segmentation and valve landmark detection in C-Arm CT for transcatheter aortic valve implantation,” IEEE Trans. Med. Imaging, vol. 31, no. 12, pp. 2307-2321, 2012.

[101] A. M. Pouch, H. Wang, M. Takabe, B. M. Jackson, C. M. Sehgal, J. H. Gorman, R. C. Gorman, and P. A. Yushkevich, "Automated segmentation and geometrical modeling of the tricuspid aortic valve in 3D echocardiographic images," in Lecture Notes in Computer Science (including subseries Lecture Notes in Artificial Intelligence and Lecture Notes in Bioinformatics), 2013, vol. 8149 LNCS, no. PART 1, pp. 485-492.

[102] T. Mansi, I. Voigt, B. Georgescu, X. Zheng, E. A. Mengue, M. Hackl, R. I. Ionasec, T. Noack, J. Seeburger, and D. Comaniciu, "An integrated framework for finite-element modeling of mitral valve biomechanics from medical images: Application to MitralClip intervention planning," Med. Image Anal., vol. 16, no. 7, pp. 1330-1346, 2012.

[103] A. Valentín, J. D. Humphrey, and G. A. Holzapfel, “A Multi-Layered Computational Model of Coupled Elastin Degradation, Vasoactive Dysfunction, and Collagenous Stiffening in Aortic Aging," Ann. Biomed. Eng., vol. 39, no. 7, pp. 2027-2045, Jul. 2011.

[104] N. Xiao, J. D. Humphrey, and C. A. Figueroa, "Multi-scale computational model of three-dimensional hemodynamics within a deformable full-body arterial network," J. Comput. Phys., vol. 244, pp. 22-40, Jul. 2013.

[105] S. Roccabianca, C. A. Figueroa, G. Tellides, and J. D. Humphrey, "Quantification of regional differences in aortic stiffness in the aging human," J. Mech. Behav. Biomed. Mater., vol. 29, pp. 618634, Jan. 2014.

[106] D. Klepach, L. C. Lee, J. F. Wenk, M. B. Ratcliffe, T. I. Zohdi, J. L. Navia, G. S. Kassab, E. Kuhl, and J. M. Guccione, "Growth and remodeling of the left ventricle: A case study of myocardial infarction and surgical ventricular restoration,” Mech. Res. Commun., vol. 42, pp. 134-141, Jun. 2012.

[107] Y.-C. Fung, Biomechanics. 1993.

[108] D. M. Ebenstein, D. Coughlin, J. Chapman, C. Li, and L. a. Pruitt, "Nanomechanical properties of calcification, fibrous tissue, and hematoma from atherosclerotic plaques," J. Biomed. Mater. Res. - Part A, vol. 91, pp. 1028-1037, 2009.

[109] G. a Holzapfel, T. C. Gasser, and R. W. Ogden, "A new constitutive framework for arterial wall mechanics and a comperative study of material models," J. Elast., vol. 61, pp. 1-48, 2000.

[110] T. C. Gasser, R. W. Ogden, and G. a Holzapfel, "Hyperelastic modelling of arterial layers with distributed collagen fibre orientations.," J. R. Soc. Interface, vol. 3, no. 6, pp. 15-35, Feb. 2006.

[111] G. a. Holzapfel, G. Sommer, and P. Regitnig, "Anisotropic Mechanical Properties of Tissue Components in Human Atherosclerotic Plaques,” J. Biomech. Eng., vol. 126, no. 5, p. 657, 2004.

[112] A. P. S. Selvadurai, "Deflections of a rubber membrane,” J. Mech. Phys. Solids, vol. 54, no. 6, pp. 1093$1119,2006$. 
[113] O. H. Yeoh, "Some Forms of the Strain Energy Function for Rubber," Rubber Chemistry and Technology, vol. 66, no. 5. pp. 754-771, 1993.

[114] N. J. Driessen, R. a Boerboom, J. M. Huyghe, C. V Bouten, and F. P. Baaijens, "Computational analyses of mechanically induced collagen fiber remodeling in the aortic heart valve.," J. Biomech. Eng., vol. 125, no. 4, pp. 549-557, 2003.

[115] H. M. Loree, S. Y. Park, and R. T. L. E. E. B, "STATIC CIRCUMFERENTIAL TANGENTIAL MODULUS TISSUE," vol. 27, no. 2, 1994.

[116] F. Auricchio and R. L. Taylor, "Shape-memory alloys : modelling and numerical simulations the finitestrain superelastic behavior," vol. 7825, no. 96, 1997.

[117] A. Wittek, K. Karatolios, P. Bihari, T. Schmitz-Rixen, R. Moosdorf, S. Vogt, and C. Blase, "In vivo determination of elastic properties of the human aorta based on 4D ultrasound data," J. Mech. Behav. Biomed. Mater., vol. 27, pp. 167-183, 2013.

[118] V. Flamini, A. P. Creane, C. M. Kerskens, and C. Lally, "Imaging and finite element analysis: A methodology for non-invasive characterization of aortic tissue," Med. Eng. Phys., vol. 37, no. 1, pp. 4854, 2015.

[119] L. Cardamone, A. Valentín, J. F. Eberth, and J. D. Humphrey, "Origin of axial prestretch and residual stress in arteries," Biomech. Model. Mechanobiol., vol. 8, no. 6, pp. 431-446, 2009.

[120] C. Schramm, A. Huber, and K. Plaschke, "The accuracy and responsiveness of continuous noninvasive arterial pressure during rapid ventricular pacing for transcatheter aortic valve replacement.," Anesth. Analg., vol. 117, no. 1, pp. 76-82, Jul. 2013.

[121] C. Capelli, J. Nordmeyer, S. Schievano, P. Lurz, S. Khambadkone, S. Lattanzio, A. M. Taylor, L. Petrini, F. Migliavacca, and P. Bonhoeffer, "How do angioplasty balloons work: a computational study on balloon expansion forces.," EuroIntervention, vol. 6, no. 5, pp. 638-42, Nov. 2010. 


\section{Annexes}

\begin{tabular}{|c|c|c|c|c|}
\hline Study & $\begin{array}{l}\text { Patient- } \\
\text { specific }\end{array}$ & Subject & TAVI step & $\begin{array}{l}\text { Deployment } \\
\text { type }\end{array}$ \\
\hline $\begin{array}{l}\text { Dwyer } \\
2009[50]\end{array}$ & No & Migration forces on TAV & Post-op & - \\
\hline $\begin{array}{l}\text { Sun } 2010 \\
{[43]}\end{array}$ & No & $\begin{array}{l}\text { Stress in leaflet and } \\
\text { hemodynamics for } \\
\text { elliptical TAV }\end{array}$ & Post-op & - \\
\hline $\begin{array}{l}\text { Sirois } \\
2011[8]\end{array}$ & Yes & $\begin{array}{l}\text { Hemodynamics before and } \\
\text { after TAVI }\end{array}$ & $\begin{array}{l}\text { Deployment } \\
\& \text { post-op }\end{array}$ & $\begin{array}{l}\text { Balloon } \\
\text { expandable }\end{array}$ \\
\hline $\begin{array}{l}\text { Capelli } \\
2012[51]\end{array}$ & Yes & $\begin{array}{l}\text { TAV deployment for } \\
\text { valve-in- valve and } \\
\text { bicuspid cases }\end{array}$ & Deployment & $\begin{array}{l}\text { Balloon } \\
\text { expandable }\end{array}$ \\
\hline $\begin{array}{l}\text { Wang } \\
2012[52]\end{array}$ & Yes & TAV deployment & Deployment & $\begin{array}{l}\text { Balloon } \\
\text { expandable }\end{array}$ \\
\hline $\begin{array}{l}\text { Hopf } 2012 \\
{[53]}\end{array}$ & Yes & $\begin{array}{l}\text { Post-op stress \& } \\
\text { displacement extraction }\end{array}$ & Post-op & - \\
\hline $\begin{array}{l}\text { Russ } 2013 \\
{[54]}\end{array}$ & Yes & $\begin{array}{l}\text { TAV deployment } \\
\text { sensitivity study }\end{array}$ & Deployment & Self expandable \\
\hline $\begin{array}{l}\text { Tzamtzis } \\
2013[55]\end{array}$ & No & $\mathrm{TAV}$ radial force & Deployment & Both \\
\hline $\begin{array}{l}\text { Kemp } \\
2013[56]\end{array}$ & No & TAV hemodynamics & Post-op & - \\
\hline $\begin{array}{l}\text { Auricchio } \\
2014[57]\end{array}$ & Yes & TAV deployment & Deployment & $\begin{array}{l}\text { Balloon } \\
\text { expandable }\end{array}$ \\
\hline $\begin{array}{l}\text { Wang } \\
2014[58]\end{array}$ & Yes & Aortic Rupture & Deployment & $\begin{array}{l}\text { Balloon } \\
\text { expandable }\end{array}$ \\
\hline $\begin{array}{l}\text { Morganti } \\
2014[59]\end{array}$ & Yes & TAV deployment & Deployment & $\begin{array}{l}\text { Balloon } \\
\text { expandable }\end{array}$ \\
\hline $\begin{array}{l}\text { Gunning } \\
2014[60]\end{array}$ & Yes & TAV deployment & Deployment & Self expandable \\
\hline $\begin{array}{l}\text { Gessat } \\
2014[61]\end{array}$ & Yes & $\begin{array}{l}\text { Post-op stress } \\
\& \text { displacement extraction }\end{array}$ & Post-op & - \\
\hline
\end{tabular}

Tab.1 Simulation studies closely related to TAVI

\begin{tabular}{|l|l|l|l|}
\hline Study & Type & Subject & $\begin{array}{l}\text { Cardiac cycle } \\
\text { concerned }\end{array}$ \\
\hline Krucinski 1993 [67] & FE & Leaflet flexure & Full \\
\hline $\begin{array}{l}\text { Grande-Allen 1998 } \\
\text { [68] }\end{array}$ & FE & Asymmetry of leaflets & Diastole \\
\hline $\begin{array}{l}\text { Grande-Allen 2000 } \\
\text { [69] }\end{array}$ & FE & Sinus \& stress & Diastole \\
\hline $\begin{array}{l}\text { Gyaneshwar 2002 } \\
\text { [70] }\end{array}$ & FE & $\begin{array}{l}\text { Dynamic analysis of leaflet \& } \\
\text { aortic root }\end{array}$ & Full \\
\hline Howard 2003 [71] & FE & $\begin{array}{l}\text { Dynamic analysis of leaflet \& } \\
\text { aortic root }\end{array}$ & Full \\
\hline
\end{tabular}




\begin{tabular}{|c|c|c|c|}
\hline Nicosia 2003 [72] & FSI & $\begin{array}{l}\text { Patient-specific aortic valve } \\
\text { model }\end{array}$ & Full \\
\hline Carmody 2003 [73] & FSI & Valve-ventricle coupling & Full \\
\hline De Hart 2003 [74] & FSI & $\begin{array}{l}\text { Leaflet material models : fiber- } \\
\text { reinforced vs homogeneous }\end{array}$ & Full \\
\hline $\begin{array}{l}\text { Arcidiacono } 2005 \\
\text { [75] }\end{array}$ & FE & $\begin{array}{l}\text { Prosthesis material : isotropic } \\
\text { vs anisotropic }\end{array}$ & Full \\
\hline Hose 2006 [76] & FSI & Closure impulse & Diastole \\
\hline Ranga 2006 [77] & FSI & Sinus & Full \\
\hline Weinberg 2007 [78] & FE & Multiscale analysis & Full \\
\hline Katayama 2008 [79] & FSI & Sinus & Full \\
\hline Viscardi 2010 [80] & CFD & $\begin{array}{l}\text { Comparison : bicuspid vs } \\
\text { tricuspid }\end{array}$ & Full \\
\hline Conti 2010 [81] & FE & Dynamic FE analysis & Full \\
\hline Labrosse 2010 [82] & FE & Dynamic FE analysis & $\begin{array}{l}\text { Full (shortened } \\
\text { diastole) }\end{array}$ \\
\hline Koch 2010 [83] & FE & Leaflet material & Diastole \\
\hline Marom 2012 [84] & FSI & $\begin{array}{l}\text { Importance of FSI over "dry" } \\
\text { FE }\end{array}$ & Mid-diastole \\
\hline Kemp 2013 [56] & FSI & Experimental validation & Full \\
\hline Borazjani 2013 [85] & FSI & $\begin{array}{l}\text { Comparison : mechanical } \\
\text { prosthesis / bioprosthesis }\end{array}$ & Full \\
\hline Marom 2013 [86] & FSI & $\begin{array}{l}\text { Collagen fiber network } \\
\text { asymmetry }\end{array}$ & Full \\
\hline Sturla 2013 [87] & FSI & Comparison "dry" FE / FSI & Full \\
\hline Kuan 2014 [88] & FSI & 2D study of bicuspid valve & Full \\
\hline
\end{tabular}

Tab.2 Numerical simulations about motion of healthy native aortic valve

\begin{tabular}{|l|l|l|l|l|l|}
\hline Study & $\begin{array}{l}\text { Imaging } \\
\text { Software }\end{array}$ & mesher & native leaflet & Calcification & Prosthesis \\
\hline $\begin{array}{l}\text { Sirois } 2011 \\
{[8]}\end{array}$ & $\begin{array}{l}\text { VTKPointpic } \\
\text { ker }\end{array}$ & HyperMesh & yes & no & SAPIEN \\
\hline $\begin{array}{l}\text { Capelli 2012 } \\
{[51]}\end{array}$ & Mimics & $?$ & yes & yes & SAPIEN \\
\hline $\begin{array}{l}\text { Wang 2012 } \\
{[52]}\end{array}$ & Avizo & HyperMesh & yes & yes & SAPIEN \\
\hline $\begin{array}{l}\text { Russ 2013 } \\
{[54]}\end{array}$ & Philips Heart & ICEM CFD & yes & yes & CoreValve \\
\hline $\begin{array}{l}\text { Auricchio } \\
2014[57]\end{array}$ & ITKsnap & Matlab & no & no & SAPIEN \\
\hline $\begin{array}{l}\text { Wang 2014 } \\
{[58]}\end{array}$ & Avizo & HyperMesh & yes & yes & SAPIEN \\
\hline
\end{tabular}




\begin{tabular}{|l|l|l|l|l|l|}
\hline $\begin{array}{l}\text { Morganti 2014 } \\
\text { [59] }\end{array}$ & ITKsnap & Matlab & yes & yes & SAPIEN \\
\hline $\begin{array}{l}\text { Gunning } 2014 \\
{[60]}\end{array}$ & Mimics & Abaqus & no & no & $\begin{array}{l}\text { Custom self- } \\
\text { expandable }\end{array}$ \\
\hline
\end{tabular}

Tab.3 Conditions for geometric reconstruction in numerical models

\begin{tabular}{|l|l|l|l|l|}
\hline Study & Aorta/Leaflet & Calcification & Prosthesis & $\begin{array}{l}\text { Zero- } \\
\text { pressure }\end{array}$ \\
\hline $\begin{array}{l}\text { Sirois } 2011 \\
{[8]}\end{array}$ & HE (Fung) [107] & none & $?$ & no \\
\hline $\begin{array}{l}\text { Capelli 2012 } \\
{[51]}\end{array}$ & HE (Mooney-Rivlin) & LE & EP (E=193 MPa) stainless steel & no \\
\hline $\begin{array}{l}\text { Wang 2012 } \\
\text { 52] }\end{array}$ & HE [96] & LE [108] & EP cobalt-chromium (E=243 GPa) & yes \\
\hline $\begin{array}{l}\text { Russ 2013 } \\
\text { 54] }\end{array}$ & Rigid/LE/HE & LE & EP Nitinol & no \\
\hline $\begin{array}{l}\text { Auricchio } \\
2014[57]\end{array}$ & HE [109] & none & EP stainless steel & no \\
\hline $\begin{array}{l}\text { Wang 2014 } \\
\text { 58] }\end{array}$ & HE [110] & LE [111] & EP stainless steel [55] & ? \\
\hline $\begin{array}{l}\text { Morganti } \\
2014[59]\end{array}$ & HE [112][113] & LE & $\begin{array}{l}\text { EP cobalt-chromium } \\
\text { (E=233GPa) }\end{array}$ & HE Nitinol [55] \\
\hline $\begin{array}{l}\text { Gunning } \\
2014[60]\end{array}$ & HE (Mooney-Rivlin) & none & no \\
\hline
\end{tabular}

Tab.4 Material models used in TAVI simulations

\begin{tabular}{|l|l|}
\hline Study & Friction Coefficient \\
\hline $\begin{array}{l}\text { Capelli 2012 } \\
\text { [51] }\end{array}$ & 0.25 \\
\hline $\begin{array}{l}\text { Wang 2012 } \\
\text { [52] }\end{array}$ & 0.1 \\
\hline $\begin{array}{l}\text { Russ 2013 } \\
{[54]}\end{array}$ & 0.2 \\
\hline $\begin{array}{l}\text { Auricchio } \\
2014[57]\end{array}$ & 0.2 \\
\hline $\begin{array}{l}\text { Morganti } \\
2014 \text { [59] }\end{array}$ & $\begin{array}{l}\text { Vertical constraint } \\
\text { instead of friction }\end{array}$ \\
\hline $\begin{array}{l}\text { Gunning } \\
2014[60]\end{array}$ & 0.25 \\
\hline
\end{tabular}

Tab.5 Coefficient of friction reported in simulation studies 